\title{
Why truck distance taxes are contagious and drive fuel taxes to the bottom ${ }^{1}$
}

\author{
Svante Mandella and Stef Proost ${ }^{\mathrm{b}}$
}

\begin{abstract}
This paper analyzes the way in which countries with international and local truck traffic decide to switch from a simple fuel tax system to a dual system of fuel and distance charge taxes. We show what drives a country to switch and how this affects the level of fuel taxes as well as incentives for other countries to also adopt the dual system. The model is partially able to explain the gradual extension of kilometer charging for trucks in Europe. The model also shows that, in the absence of diesel cars, the gradual introduction of kilometer charges will make fuel taxation for trucks virtually disappear and will lead to a system where truck use is (1) taxed mainly based on distance, (2) is taxed too heavily, and (3) where highest distance taxes are expected in transit countries with a strong market position. When the fuel tax must in addition serve as an externality tax for diesel cars, the introduction of distance charges for trucks will give rise to diesel taxes that are lower than the external cost of diesel cars. For trucks, this leads to a sum of diesel taxes and distance charges that are higher than the external cost of trucks.
\end{abstract}

Keywords: Diesel taxes, fuel taxes, kilometre charges, tax competition, pricing of trucks

JEL codes : H23,H73,L91, R48

aRoyal Institute of Technology / VTI, Stockholm

Svante.Mandell@vti.se

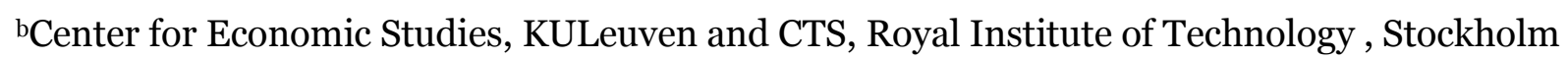

\footnotetext{
${ }^{1}$ We thank the editor and two referees for very useful comments. The paper benefited from comments of participants of the ITEA meeting (2014), seminar participants at TUDresden (2014), Stockholm (2014), Toulouse (October 2014), Oslo (2015) and Brussels (2015). Special thanks to Amihai Glazer, Linda Cohen, Inge Vierth and Ruth Evers for useful comments. Svante Mandell acknowledges the support of CTS. Stef Proost acknowledges the support of CTS and of the EIBurs research program administered by the EIB.
} 


\section{Introduction}

This paper addresses how international competition affects the choice of tax instruments for road freight transport. The main tax instrument used in most countries is still an excise tax on diesel fuel. As international trucks are able to decide in which country they refuel, this has given rise to international fuel tax competition. This has been the case in Europe over the last 25 years, where member states kept almost full authority on excise taxes, while simultaneously the international road freight haulage expanded strongly due to EU trade integration. Since 2000, the diesel excise tax has been supplemented in several EU countries by a distance charge. Technological development has made it possible, and economically feasible, to employ, e.g., GPS-based charging systems. Many other federal governments where member states are able to add state gasoline taxes face the same policy issue (e.g., the US, India, and Australia).

The main purpose of this paper is to provide a deeper understanding of the dynamics of the tax competition game that result when a kilometer charge for trucks becomes available and, based on this, propose policy conclusions. Using a simple analytical setting with two countries, we analyze how the addition of a kilometer charge for trucks changes the tax competition game. Distance charges, unlike diesel taxes, must be paid when a truck uses the roads of that country. Consequently, any country that introduces the distance charge can reduce its fuel taxes while threatening the tax base of those neighbors that have not yet enacted a distance charge. As a response, the neighboring countries will also implement distance charging, resulting in the spread of high distance charges and very low fuel charges.

More precisely, we offer the following results. Consider first the case where there are other tax instruments available for taxing diesel cars apart from fuel excises. Then if diesel taxes are the only instrument available to tax trucks, in the Nash equilibrium, the diesel taxes may be lower or higher than the external and infrastructure costs of trucks. The taxes will typically be low in countries of equal size when there is intensive fuel tax competition. When countries differ in size, the tax in the smaller country will be lower than that in the larger country. This confirms results from literature (Kanbur \& Keen, 1993). When distance charges are also available and their implementation costs are low, all countries adopt distance charges for trucks and fuel taxes are driven to the bottom. The distance charges will all be higher than the external costs while the margin will be highest in the smaller countries. This is mainly driven by smaller countries having a larger share of international relative to domestic transports. Moving from diesel taxes to distance charges can therefore be welfare decreasing as one adds a very powerful instrument for tax exporting. 
Consider next the case where the diesel excise is also the main instrument to regulate the use of diesel cars. If there are no distance charges, the fuel tax will have to balance the optimal taxation of diesel cars and of trucks. As only one instrument is used, it is impossible to set the diesel fuel tax equal to the external costs of trucks and cars so the tax will be a weighted average between the external costs of diesel cars and trucks and margins on international trucking. Again, the tax competition effects on the fuel market for international trucks may increase or decrease the tax, but diesel use by cars is typically less vulnerable to tax competition since cars make less international trips. The result will be that the diesel tax in one country reacts less strongly to tax changes in a neighboring country. Introduce now distance charges for trucks. Both countries will use distance charges and fuel excises. The sum of distance charges and diesel excises will be higher than the external cost for trucks and the diesel tax will be lower than the external costs of diesel cars. These results carry over to the case of pure transit countries with a strong market position. In this case, there is also no guarantee that the introduction of distance charges improves pricing from a welfare perspective. These are important findings from a policy perspective.

The paper is organized as follows. In section 2 we illustrate some of the recent truck charging developments. In section 3 we review the literature. In section 4 we set up the model. Section 5 is devoted to the analysis of the game where fuel tax is the only instrument but where diesel cars are unimportant or can be taxed using other instruments. We illustrate the circumstances where a Nash equilibrium exists in pure strategies and discuss the characteristics of the equilibrium. Section 6 analyzes the effects of the introduction of a distance charge showing that it has a large impact as a result of zero fuel taxes. Section 7 presents a numerical example that shows how present German fuel taxes and distance charges can exist in a Nash equilibrium in our setting. Section 8 contains an extension of the model that allows us to study the behavior of a transit country, e.g., Switzerland. In Section 9, we introduce diesel cars that must also be taxed using a fuel tax. Section 10 presents the major policy conclusions.

\section{Charging trucks for road use}

Almost all countries charge excises for diesel fuel used by trucks. Because trucks can cover 1000 to $2000 \mathrm{~km}$ with a single tank, countries or regions engage in fuel tax competition. In the US, state diesel excise taxes add 50\% or more to the federal diesel excise. In India, states are also responsible for an important part of the total diesel excise. Within the EU, where there is no federal diesel excise tax, some smaller countries have chosen a strategy of low excise taxes, which brought the EU to negotiate a minimum tax level for diesel fuel. In 2012, Germany charged an excise of 0.47 Euro/liter while Luxemburg, a tiny neighbor, charged 
only the EU minimum of 0.30 Euro/liter (Hylén, Kauppila, Chong, 2013). In addition to the diesel excise taxes, the EU member states can charge road user fees using three mechanisms: toll roads (e.g. France, Spain, and Italy), distance-based charges (charge per km via electronic tracking) and finally by a time-based vignette (annual, monthly, or weekly payment per vehicle). The main conditions are that the payment system is non-discriminatory and charges for infrastructure costs. Later, charging for external costs (air pollution, noise, congestion) ${ }^{2}$ was also allowed (see Vierth \& Schleusser, 2012). In Europe, the Eurovignette paid in one country also allowed the user to travel in the network of other participating countries. This was originally introduced in 1999 in 12 countries. As all participating countries were obliged to agree on an amount, it took many years to agree on subsequent amendments for inflation and environmental damage estimates ${ }^{3}$. This resulted in low amounts for the Eurovignette and many countries dropping out. Only five countries (Belgium, Denmark, Luxemburg, Netherlands and Sweden) continue to use the Eurovignette system.

Technological progress in charging techniques meant that several countries with transit wanted to introduce distance-based charging and quit the Eurovignette system. In 2001, Switzerland (not an EU member) replaced its vignette system by a kilometer charging system that charged trucks much more than before. The neighboring countries followed: Austria (a transit country parallel to Switzerland) in 2004, Germany in 2005 (although it wanted to start earlier), Czech Republic in 2007, Slovakia in 2010 and Poland in 2011. Other countries (e.g. Belgium) are preparing for its introduction. Some other EU countries had already developed a tolling system for most of their motorways (France, Italy and Spain) but considered adding electronic distance charging for the non-tolled truck roads. Appendix 1 illustrates the different charging systems in place in Europe in 2012. This shows a clear pattern, as the introduction of distance charges was strongly correlated geographically. The member states in the center of Europe tend to use distance-based charges. The transaction costs associated with a distance-based system vary between 10 and $20 \%$ of the revenues (see Hamilton \& Eliasson, 2013), which is probably much larger than the transaction costs of fuel excise taxes. Peripheral states use vignettes or no charges at all apart from fuel taxes. These observations are our main motivation for analyzing the reasons that one country moves to the

\footnotetext{
${ }^{2}$ See directive 1999/62/EC followed by directives 2006/38/EC and 206/103/EC.

${ }^{3}$ Weismann (2013) describes the long negotiation process (3 years) to reform the Eurovignette directive. The negotiation process involved the Commission, the Parliament and the Council.
} 
more costly dual system, how this may force other countries to follow suit, and what the tax levels are that this may generate.

Figure 1 (Hylén et.al., 2013) presents the total road use charges for a 40-ton truck with a domestic haul of $400 \mathrm{~km}$. This calls for several observations. First, the overall charge has been on the rise since 2000. Second, the countries with the lowest charges are those that do not have distance charges or tolls and rely only on fuel taxes and the Eurovignette. 4

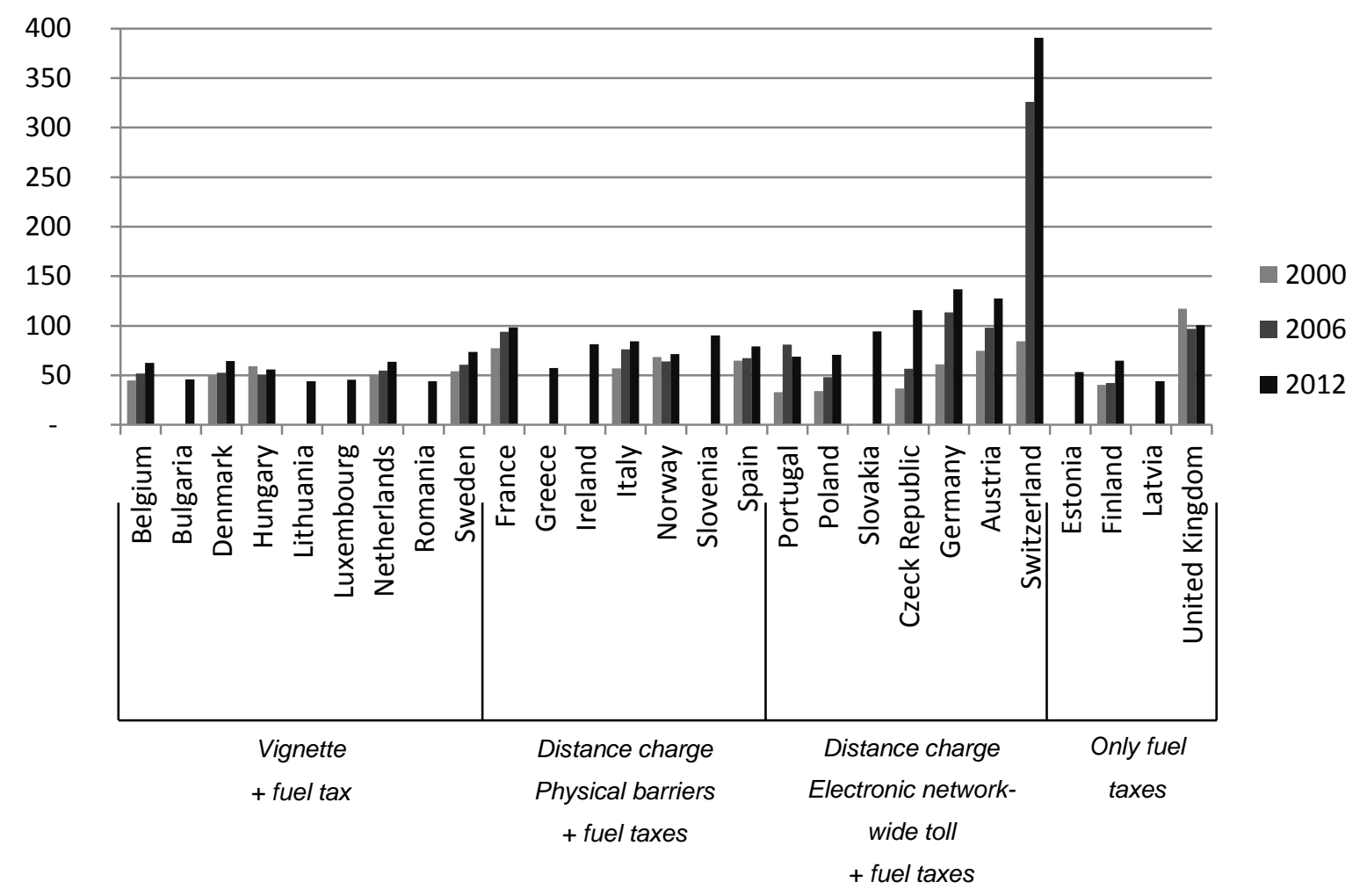

Figure 1 Total charges in Euro for a standard domestic haul of $400 \mathrm{~km}$ by a 40 ton truck. Charging policy as of 2012 (source Hylén et.al., 2013)

There are four interesting transition features to note. First, all distance-based charging generated much more revenues than the vignettes it replaced. In Germany distance charge revenues were 6.5 times larger than the previous Eurovignette revenues. This is curious as both systems are meant to pay for the actual costs of road building and maintenance as well as for environmental costs. The reason that the Eurovignette system generated such low

\footnotetext{
${ }^{4}$ Ireland (very high registration tax for trucks) and the UK (high fuel tax) are exceptions. As islands, however, they can afford different tax levels.
} 
revenues was that it was the lowest common denominator on which all participating countries could agree. The second point we note is that the distance charging schemes discriminate much more in function of conventional air pollution than the Eurovignette systems do. In the case of Germany, this was disguised "favoring" of the home carriers since the German government gave large subsidies for cleaner German trucks (Vierth, Schleusser, 2012). Third, if one compares the sum of distance charges and fuel taxes in Figure 1, one finds that Switzerland charges 3 to 4 times more per kilometer than the other EU countries with distance charges. The main reason is the strategic position of Switzerland as a transit country. Of course, Austria is also a transit country, but the distance charges in Austria are capped by EU regulations. Finally, note for later that in Figure 1 Austria and Germany have more or less the same total charges (fuel and distance charge) for a standardized haul, but the composition of the charges is different. Austria has a higher distance charge (0.35 vs 0.18 Euro/vehicle km) and a lower fuel charge (0.40 vs 0.47 Euro/ liter diesel) than Germany. This looks like an ideal mix for Austria, a small country that faces a lot of transit traffic and tries to maximize its share in the fuel market for international trucking.

\section{Literature review}

We will rely on three types of literature. There is first the more general public finance literature on tax competition, second the literature on policy competition and pricing in transportation networks, and finally, there is the empirical literature on tax competition for diesel fuel.

The major insights we will use come from the tax competition literature, which is surveyed in Wilson (1999). We will draw upon the insights from Kanbur and Keen (1993). They show how the tax setting behavior of Leviathan governments depends on the relative size of a country. Smaller countries can gain by undercutting their neighbors as they have more to gain from cross-border shopping than from domestic tax revenues.

The literature on policy competition between governments in the transport sector has been reviewed in De Borger \& Proost (2012). More in particular, they review the competition of private or public agents that may each control part of a transport network. The simplest model setups are the parallel network and the serial set up. In the parallel setup (De Borger, Proost, Van Dender, 2005), international trucks can choose between two links (countries) and the countries compete in tolls (and in infrastructure capacity), taking into account that there is also domestic traffic on the network. Each country will charge more than the external cost but the margin will be restricted by the competition for transit traffic and by the efficiency loss it implies for domestic traffic. We will use, more intensely, a serial network type set-up (De Borger, Dunkerley, Proost, 2007; 2008; Mun \& Ahn, 2008) where a truck 
must go through at least two countries to complete its trip. In this case each country charges a monopoly margin that is limited by the deadweight loss on domestic traffic. Overall, there is a risk of double marginalization and thus of overcharging for the use of the road network. In these two papers, trucks are charged per trip and they cannot escape the charge if they use the road network of a given country. In our paper we drop this assumption and include two tax instruments in the analysis. We start with the fuel excise taxes that can be escaped by fueling abroad and give countries the option to add a distance charge. We will mainly deal with pricing the use of existing capacity and do not discuss the relationship between kilometer charges, congestion levels and infrastructure supply. The European regulation capped distance charges to the average infrastructure charges, which can be important for forcing member countries to introduce efficient charges (see Van der Loo \& Proost, 2013).

The competition on excise taxes for diesel fuel in the EU has been studied intensively. All authors assumed Leviathan behavior for the governments. Evers, de Mooij and Vollebergh (2004) studied a panel data set for 17 countries (1978-2001) and estimated Nash reaction functions for diesel excises. They found strong evidence of tax competition. When neighboring countries increase their fuel excise tax by 10\%, an average EU country increases its tax by 2 to $3 \%$. They also found that the imposition of minimum tax rates has increased overall excise levels but the intensity of tax competition has not decreased. Rietveld \& van Woudenberg (2005) analyzed the setting of gasoline and diesel taxes and found strong tax competition effects for diesel excise taxes in Europe. Paizs (2013) confirms the evidence on diesel excise competition. He also finds that smaller countries tend to charge lower fuel excise taxes as predicted by Kanbur and Keen (1993). The focus of our paper is not on empirical validation but on understanding the transition from fuel excises to distance charging for road use by trucks.

\section{Assumptions and model elements}

\section{Assumptions}

We distinguish between (1) assumptions that are essential for the results and (2) simplifying assumptions that are made for expositional purposes.

Two assumptions are essential since they specifically drive the results. The first is that governments maximize the welfare of their citizens rather than behaving as a Leviathan. The second is that governments behave non-cooperatively and play one shot in pure strategies. We justify these assumptions in the next section.

We use five simplifying assumptions that make the model more tractable but can be relaxed. 
First we assume that the fuel efficiency of trucks is fixed. This is only a mild assumption as trucks are designed to be used in many countries and their fuel efficiency will be a function of the expected fuel taxes and fuel efficiency regulations in the different countries where the truck is used.

The second assumption is that the trucks are homogeneous and the external cost of trucks differs among countries while being constant per kilometer and independent of the amount of total truck use in a given region. We consider three types of external costs: wear \& tear of infrastructure, local air pollution and congestion. The homogeneity assumption is problematic for road damage, as this depends on the design and loading of the truck. In principle congestion also depends on the volume of truck use and is therefore not fixed. There are two lines of defense for this assumption. Consider first the short term: as trucks are only 5 to $20 \%$ of total volume of road use, small variations in the total truck volume due to truck tax variations may justify somewhat the constant external cost assumption. Consider next the long term with variable road capacity; if we have constant returns to scale in infrastructure extension, the external congestion cost becomes a constant. For this reason we will use external congestion cost and infrastructure cost as synonyms throughout this text. Trucks also differ in the emission of traditional air pollutants, which is more or less a transition problem as new regulations are only imposed on new trucks. Even so, excluding this aspect from our model will only have a minor impact on the qualitative results. What is missed is a potential sorting effect due to cleaner trucks being used in countries with high charges for less clean trucks. We return to this issue in the concluding section.

The third assumption is that we use a model consisting of only two countries; $A$ and $B$. We assume that both countries take the behavior of the other country as given. This is more easily justified in the case of many countries. As long as all countries are identical, we can generalize the model to $n$ countries that interact. For instance we could consider a Löschian model where space is filled with identical countries that have a hexagonal shape: where every country has always six neighbors that generate international traffic and set fuel taxes and distance charges. In section 7 we generalize the model by inserting a small transit country in between the countries of origin and destination of the truck trip.

The fourth assumption is that we can isolate the charging of trucks and of cars. This can be justified by assuming that either the share of diesel cars is negligible or that governments use other types of car taxes (registration or purchase taxes) to align the taxation of diesel cars to the taxation of gasoline, as it is in their interest to separate both users of diesel fuel. We will relax this assumption in Section 9. 
Finally, our assumption of constant fuel efficiency, combined with homogeneous trucks, implies that a fuel tax and a distance charge would be perfect substitutes for domestic transport. This is a strong assumption but assists us in making our point.

Objective function and behavior of the governments

We assume that country governments maximize the sum of the consumer surplus of domestic trucking ${ }^{5}$ plus part of the consumer surplus of international truck transport plus the total tax revenues minus the total external costs within the country (infrastructure costs plus external congestion costs on local car use and local environmental costs). As all international trips correspond to a transaction where both countries gain, we assume that they share equally in the gains.

Using the sum of consumer surplus plus tax revenues minus external costs is a rather normative approach for government behavior. A popular alternative among economists is the Leviathan assumption (Kanbur \& Keen, 1993) where governments simply aim to maximize total tax revenues. The Leviathan assumption is also at the basis of the empirical work on diesel excises cited above, but the Leviathan assumption itself is not tested empirically in that empirical work. There is however some factual evidence for our less extreme assumption. First, whenever there is a proposal to raise the level of fuel excises, local truck drivers lobby strongly in opposition and governments often give in, meaning the consumer surplus of trucks counts to some extent. Second, the distance charges are strongly differentiated as a function of the emission rates of trucks (Vierth \& Schleusser, 2012). This implies that environmental benefits also matter.

We will focus only on Nash equilibriums in pure strategies in a one shot game. Mixed strategies are an option but it is difficult to rationalize them as the outcome of a government decision process. Most of the literature (Kanbur \& Keen (1993) and surveys of Wilson (1999) and of De Borger \& Proost (2012)) do not consider mixed strategies for governments. Repeated games offer a larger strategy space but this is again difficult to justify for democratic governments: it is difficult to punish one coalition for what the previous coalition did.

\footnotetext{
${ }^{5}$ Later, we include diesel cars. Then the government also cares for the consumer surplus of domestic car users.
} 


\section{Behavior of domestic and international trucks}

In each country there are both domestic and international truck trips, and the entire trucking industry is competitive. Domestic truck traffic only uses the local road network and buys fuel locally ${ }^{6}$. International trips use the road network at home and the road network of another country. The international hauler buys more fuel in the cheapest country. Figure 2 presents the model set up.

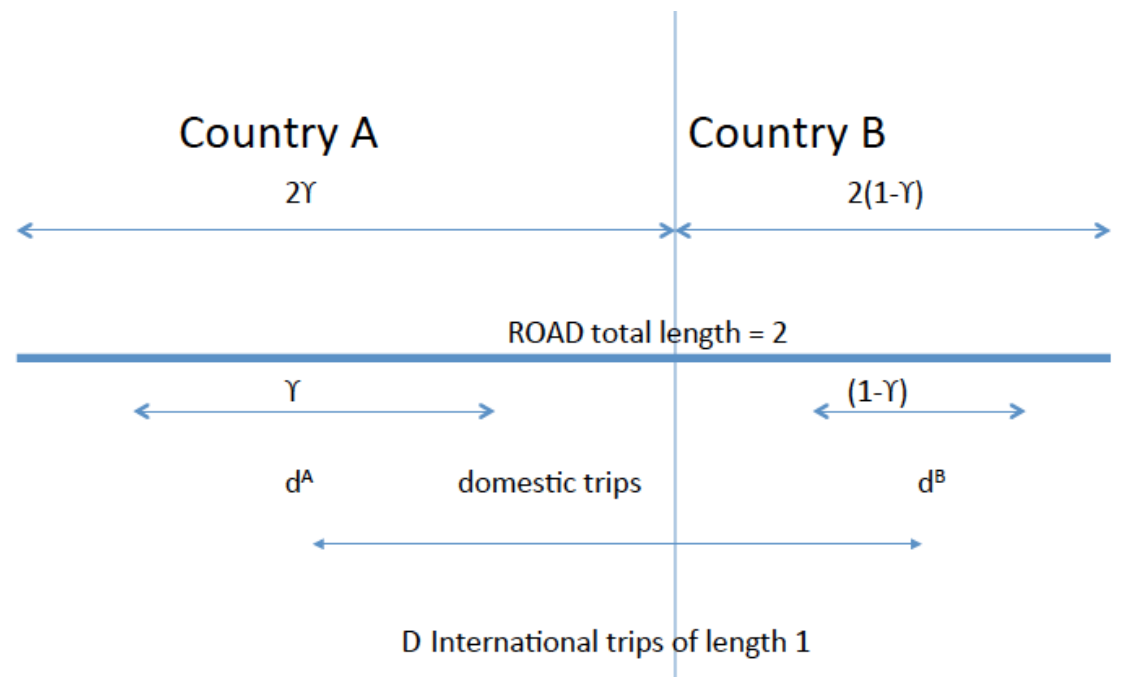

\section{Figure 2. Model set up}

Total length of the road running through both countries equals 2. Both countries have the same spatial density. Whenever countries differ in size, we take country $A$ as the bigger country. Country $A$ has size $2 \gamma$ and country $B$ has size $2(1-\gamma)$, where $\gamma \in[0.5,1]$. On average, domestic trips will cover a distance $\gamma$ in country $A$. In country $B$, trips will be of length $(1-\gamma)$.

\footnotetext{
${ }^{6}$ In some tax competition models (Kanbur \& Keen, 1993 and others), tax competition takes the form of shopping abroad, so incurring transport costs to buy goods abroad. This makes more sense for consumer goods (tobacco, alcohol). In the case of trucks the additional costs of the driver and truck make it unlikely for domestic truck trips to make this pure shopping trip.
} 
International trips will be of length 1 with a part $\gamma$ in country $A$ and a part $(1-\gamma)$ in country $B$. The trip length is fixed but the number of trips will be variable. ${ }^{7}$

Trucks face three types of costs (all expressed per unit length): costs before taxes $c$, fuel tax $t_{i}$ ( $i=A, B)$ and a kilometer charge $T_{i}(i=A, B)$. The total cost is denoted by $g$ for the generalized cost for local trucks and by $G$ for international truck traffic.

The local demand functions (number of trips) equal:

$$
\begin{aligned}
& d_{A}=a-b g_{A} \\
& d_{B}=a-b g_{B}
\end{aligned}
$$

Where $a$ and $b$ are non-negative parameters. The number of international trips will, by construction, be the same in both countries. The international demand function (number of trips) is:

$$
D=\alpha-\beta \cdot G
$$

Where $\alpha$ and $\beta$ are non-negative parameters. For ease of exposition, we will sometimes use the assumption that international truck demand is totally inelastic.

The generalized costs of a domestic trip take into account its relative distance: ${ }^{8}$

$$
\begin{aligned}
& g_{A}=\gamma\left(c+t_{A}+T_{A}\right) \\
& g_{B}=(1-\gamma)\left(c+t_{B}+T_{B}\right)
\end{aligned}
$$

And the generalized cost of international trips equals the sum of costs in both countries:

$$
\begin{aligned}
& G=c+\gamma T_{A}+(1-\gamma) T_{B}+\sigma\left(t_{A}, t_{B}\right) t_{A}+\left(1-\sigma\left(t_{A}, t_{B}\right)\right) t_{B} \\
& \sigma\left(t_{A}, t_{B}\right)=\gamma-\rho\left(t_{A}-t_{B}\right) \\
& \sigma\left(t_{A}, t_{B}\right)=1 \quad \text { when } t_{B}-t_{A} \geq(1-\gamma) / \rho \\
& \sigma\left(t_{A}, t_{B}\right)=0 \quad \text { when } t_{A}-t_{B} \geq \gamma / \rho
\end{aligned}
$$

\footnotetext{
${ }^{7}$ Charging more for fuel or per km may make trips shorter and may substitute shorter domestic trips for international trips. This is not considered in this paper.

${ }^{8}$ An alternative set-up would be that all domestic trips have the same length irrespective of the country.
} 
International haulers minimize their fuel costs by buying more fuel in the cheaper country they drive through. We use a simple reduced form formulation for this cost minimization process of the haulers. Equation (4) represents the refueling choices of the haulers by use of a simple linear formulation for the share of fuel $\sigma\left(t_{A}, t_{B}\right)$ bought in country $A$. When the difference in taxes is larger than a given constant, a hauler only buys fuel in the cheapest country. The parameter $\rho$ is a measure of the intensity of tax competition: a small $\rho$ means that an increase in the fuel tax difference does not strongly affect the market share $\sigma$ in the international trucking fuel market.

When fuel taxes are equal in both countries, the fuel purchases are proportional to the size of the country. One could also use more complex formulations like the logistic function but results do not truly depend on this. The fuel market share function implies that the generalized cost of international haulers is a non-decreasing function of the fuel taxes in both countries:

$$
\begin{aligned}
\frac{\partial G}{\partial t_{A}} \geq 0, \frac{\partial G}{\partial t_{B}} \geq 0 \\
\frac{\partial G}{\partial t_{A}}=\sigma-\rho\left(t_{A}-t_{B}\right) \\
\frac{\partial G}{\partial t_{B}}=(1-\sigma)+\rho\left(t_{A}-t_{B}\right)
\end{aligned}
$$

For solutions to be interesting we need to assume that there is at least one solution with positive local and international truck demand.

There is a fundamental difference between the two tax instruments. International transport must pay distance charges in both countries. There is thus an element of double marginalization at play as both countries may apply a mark-up on the distance charge above what is motivated by external costs. The same does not occur for fuel taxes, where, within limits, fuel may be purchased and taxed for in the country with the lowest tax (which also means lowest price in our setting). The degree to which the transport sector changes behavior as a response to differences in fuel tax is handled by $\rho$. When $\rho \rightarrow 0$, the share in country A, $\sigma\left(t_{A}, t_{B}\right)$, converges to $\gamma$, the relative size of A. Then the generalized cost simplifies to $G=c+$ $\gamma\left(T_{A}+t_{A}\right)+(1-\gamma)\left(T_{B}+t_{B}\right)$ and the two instruments become perfect substitutes. The choice of which instrument to use then only depends on which is cheapest to implement and operate. 


\section{Fuel Tax setting behavior of governments in the absence of diesel cars}

We now have all the elements to study the behavior of governments. We first concentrate on fuel tax as the only instrument and study the Nash equilibrium for this situation. In the next section we will add distance charging as a tax instrument. Throughout sections 5 and 6 we will assume that there are either no diesel cars or that they can be taxed using additional instruments so that they do not intervene with the optimal fuel tax for trucks.

The structure of the first order condition

Each country's government maximizes the sum of consumer surplus of local trips (cs in (6)) plus half of the consumer surplus $(C S)$ of international trips. ${ }^{9}$ In addition, governments take into account their own tax revenues minus external costs as well as implementation costs ${ }^{10}$. As we always have fuel taxes, we only consider the implementation costs ( $I T_{i}$ ) of kilometer charges. The consumer surplus cs and the demand $d$ for domestic trips are a function of the generalized price $g_{A}\{\}$ defined in (3) and therefore of the local fuel tax. The consumer surplus $C S$ and volume of international traffic $D$ are a function of the generalized price $G\{\}$ as defined in (4) and therefore a function of the fuel taxes and distance charges in the two countries.

The objective function of the government in country $A$ becomes:

$$
\operatorname{cs}_{A}\left\{g_{A}\{.\}\right\}+d_{A}\{.\}\left(\gamma t_{A}+\gamma T_{A}-\gamma e c_{A}\right)+0.5 \operatorname{CS}\{G\{.\}\}+D\{.\}\left(\sigma t_{A}+\gamma T_{A}-\gamma e c_{A}\right)-I T_{A}
$$

Note the difference between the tax revenue per trip and the external cost. The external cost is fixed per trip (or per $\mathrm{km}$ ) and the only way to reduce it is to reduce the volume of trips via the fuel tax or the distance charge.

\footnotetext{
${ }^{9}$ As all international trips correspond to a transaction where both countries gain, we assume that they share equally in the gains.

${ }^{10}$ Our formulation neglects the general equilibrium effect of road taxes and fuel taxes on the price of products. A competitive international haulage sector will pass on the large part of its additional taxes onto consumers and producers. This may be a motive for a government to restrict taxes on road freight to the marginal external costs.
} 
In order to study the Nash equilibrium in fuel taxes, we derive the first order condition with respect to fuel tax $t_{A}$ and set the distance charges $T_{A}$ and $T_{B}$ to zero. Taking country $A$ and differentiating the objective function (6) with respect to $t_{A}$, we get the following optimality condition:

$$
-\gamma d_{A}+\gamma \frac{\partial d_{A}}{\partial t_{A}}\left(t_{A}-e c_{A}\right)+\gamma d_{A}-0.5 D \frac{\partial G_{A}}{\partial t_{A}}+\frac{\partial D}{\partial t_{A}}\left(\sigma t_{A}-\gamma e c_{A}\right)+\frac{\partial \sigma}{\partial t_{A}} \sigma D t_{A}+\sigma D=0
$$

The optimal fuel tax is defined by combining seven effects. The first effect captures the change in consumer surplus on the market for domestic transportation. This is entirely cancelled out by the tax revenues from domestic transportation in the third term because this is a transfer within the country. Remaining effects on the domestic market are captured by the second term, which multiplies the change in domestic transport demand (measured as length $\gamma$ times the number of trips) with the net taxes of external costs.

The last four terms deal with international transport. First, note that the change in consumer surplus (fourth term) and the change in tax revenues (last term) do not cancel out in a way corresponding to what we see on the domestic market. This is not surprising since part of the tax is paid by haulers from country $B$. There are three tax effects. The first, in term five, follows from the change in demand due to the change in tax. Term six follows from the change in tax that influences the choice of where to fuel. The last effect, in term seven, is the direct tax revenue effect capturing the share of total international demand that will buy fuel in country $A$.

We explore the fuel tax choice in three steps. We start by discussing the case where demand for truck trips is inelastic (PROP 1). Next we analyze the case of price-elastic truck demand but where countries are fully symmetric (PROP 2), and in the last step we discuss the more general asymmetric case (PROP 3).

Fuel tax equilibrium with price-inelastic truck demand

If both domestic and international trips are fixed, the objective function of both governments reduces to maximizing fuel tax revenues from international traffic. The reason is that total external costs are fixed and taxes on national trucking are a pure transfer for a government pursuing national welfare. This leads to the following proposition:

PROP 1 When domestic and international truck demands are fixed, the reaction functions for the truck diesel taxes $t_{A}\left(t_{B}\right), t_{B}\left(t_{A}\right)$ and the Nash equilibrium in pure strategies $t^{N_{A}}, t^{N_{B}}$ are: 


$$
\begin{aligned}
& t_{A}\left(t_{B}\right)=\frac{\gamma}{3 \rho}+\frac{t_{B}}{3} \quad t_{B}\left(t_{A}\right)=\frac{1-\gamma}{3 \rho}+\frac{t_{A}}{3} \\
& t_{A}^{N}=\frac{1}{8 \rho}+\frac{2 \gamma}{8 \rho} \quad t_{B}^{N}=\frac{1}{8 \rho}+\frac{2(1-\gamma)}{8 \rho}
\end{aligned}
$$

\section{where an equilibrium in positive fuel taxes always exists.}

\section{Proof: see Appendix 2}

The reaction functions and the Nash equilibrium are represented in Figure 3. The reaction functions are upward sloping: as total demand is fixed but fuel demand is price sensitive, both countries follow their neighbor's tax increases, but only partially, in order to gain market share. The Nash equilibrium is also within the zone where both countries share the market. In the upper left zone $(\sigma=0)$, tax $t_{A}$ is so much larger than $t_{B}$, that country B holds the entire international trucking fuel market. In the lower right zone $(\sigma=1)$ country A holds the entire international fuel market.

The Nash equilibrium has two characteristics that will re-appear in many cases we discuss. The first is that the tax rates are a decreasing function of the "openness" of the fuel market $\rho$. The openness will be larger when international trips are shorter (countries of smaller size) and when there are more options for using larger fuel tanks (some countries have attempted to prohibit them). The second feature is the role of the relative size of the countries. The tax rate of the larger country (A) is increasing in size $(\gamma)$. This is the result of our fuel market share equation $\sigma\left(t_{A}, t_{B}\right)=\gamma-\rho\left(t_{A}-t_{B}\right)$. The market share equation has two parts: a base part $(\gamma)$ and a competitive part $\left(-\rho\left(t_{A}-t_{B}\right)\right)$. A larger country implies that international trucks cover, on average, a larger distance within the country, implying a larger market share when fuel taxes are equal: this is the larger base part $(\gamma)$. The smaller country has more to gain by undercutting the large neighbor and in this way stealing part of its tax base. When both countries have the same size, the equilibrium taxes are equal to $\frac{1}{4 \rho}$. 


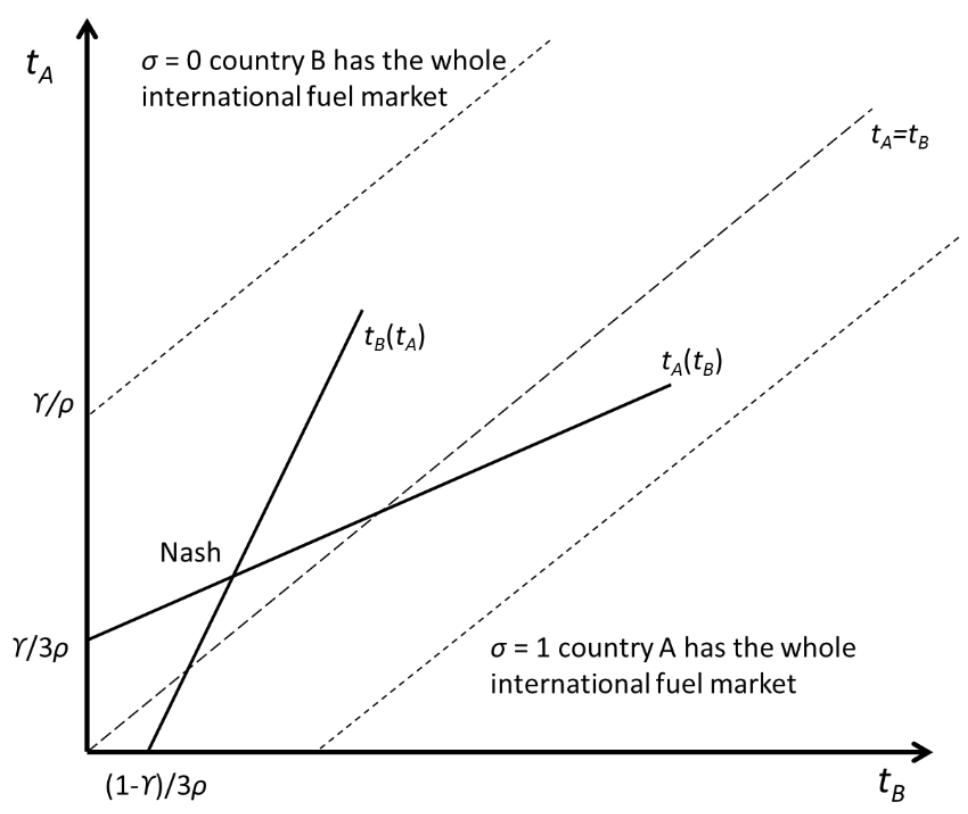

Figure 3 Reaction functions for truck fuel taxes when truck traffic is inelastic

Symmetric fuel tax equilibrium with elastic truck demand

We now add in price sensitivity of the domestic and international truck market. Using again the first order condition (7), and imposing symmetry, we have an implicit ${ }^{11}$ solution for the Nash equilibrium. The solution entails a Nash equilibrium as long as the fuel tax competition is low enough to ensure that one country cannot increase welfare by switching to set fuel taxes equal to external costs ${ }^{12}$.

${ }^{11}$ Equation (9) is an implicit function in $t_{A}$ as the tax rates are still present in $D$.

${ }^{12}$ This is further discussed below where we, in Equation (10), derive an expression for what is "low enough." 
PROP 2 When domestic truck demand and international truck demands are price dependent, and fuel tax competition is low, the symmetric Nash equilibrium in pure strategies for fuel taxes is:

$$
\begin{aligned}
& t_{A}^{N}=t_{B}^{N}=\frac{z}{z-2 \rho D} e c-\frac{\gamma}{z-2 \rho D} D \\
& \text { where } z=\left(\frac{\delta d}{\delta t_{A}}+\frac{\delta D}{\delta t_{A}}\right)
\end{aligned}
$$

\section{When fuel tax competition is sufficiently high, no Nash equilibrium in pure strategies exists.}

\section{Proof: in Appendix 3}

Consider first the case where fuel tax competition is not too strong and allows for a Nash equilibrium in pure strategies. To understand the level of the fuel taxes consider the extreme case where there is no international traffic at all $(D=0)$, and (9) reduces to charging the external cost. This is expected because the fuel efficiency is fixed, so the external cost is strictly proportional to the distance driven. The best a policy maker can then do is charge the marginal external cost. This is in line with efficiency results for the production sector when there are externalities (Diamond \& Mirrlees, 1971; Mayeres \& Proost, 1997).

Whenever there is international truck transport, the equilibrium fuel tax, if it exists, will consist of two elements: an external cost component (first term with $e c$ ) and a tax revenue component (second term with $D$ ). We see that the first component is always smaller than the external cost and that the second component is always positive. This means that the fuel tax can be larger or smaller than the external cost. We have three elements playing a role in the size of the fuel tax compared to the external cost.

First, raising the fuel tax above the external cost distorts the allocation of domestic transport so that the more important domestic transport and its fuel price sensitivity are, the closer the fuel tax will stay to the external cost. Second, a larger price-sensitivity of international traffic ( $\rho$ ) restricts the possibility of making an extra margin on the fuel tax, therefore restricting the fuel tax (cfr; $2^{\text {nd }}$ component of (9)). Third, the more important the international truck volume $D$ is, the larger the revenue-raising component will be; $t^{N}$ is increasing in $D$ (proof in Appendix 3).

Consider next the case where fuel tax competition becomes very intense. We know that this lowers the fuel tax. To understand the non-existence of the Nash equilibrium in pure 
strategies, examine the components of the tax-setting government's objective function when fuel tax competition increases. Assume that the number of international trips is fixed. Lowering the fuel tax below the external cost creates a welfare loss on the market of local truck trips. As international trips are fixed, the consumer surplus and external cost of international trips stay constant. The fuel tax revenue from international trips, however, decreases with lower taxes when the fuel tax decrease is matched by the neighbor country. So one component of the national welfare becomes more negative and the positive component of national welfare (tax revenues) decreases. There will exist a level of fuel tax, denoted $t_{A}^{*}$, where the national welfare is equal to what can be achieved by simply charging a fuel tax on local traffic equal to the external cost and foregoing the revenue from fuel sales on international trips.

We can determine this critical value of fuel tax competition intensity as follows. We need the critical value of $\rho$, the tax competition intensity, such that $t_{A}^{*}$ is equal to the tax in the potential symmetric Nash equilibrium, given fixed $D$. (proof in Appendix 3):

$$
t_{A}^{*}=0.5\left[2 \mathrm{ec}+\frac{2 D}{b}-\sqrt{\frac{2 D}{b}} \sqrt{4 e c+\frac{2 D}{b}}\right]=t_{A}^{N}=\frac{0.5 \mathrm{~b}}{0.5 \mathrm{~b}+2 \rho^{*} D} e c+\frac{0.5}{0.5 \mathrm{~b}+2 \rho^{*} D} D
$$

Solving this expression for $\rho^{*}$ yields

$$
\rho^{*}=\frac{b((b-1) D+\sqrt{D(D+2 b \text { ec })})}{4 D(D+b \text { ec }-\sqrt{D(D+2 b \text { ec })})}
$$

Which takes on positive values.

The critical $\rho^{*}$ is then defined as the $\rho$ that produces $t^{*}$ in equation (10). The critical $\rho^{*}$ will be a function of the external cost $e c$, the price sensitivity of local traffic $b$ and the importance of international traffic $D^{13}$.

\footnotetext{
${ }^{13}$ Consider as an example the following values: $e c=4, D=10$ and $b=1$, a critical fuel tax value of $t_{A}^{*}=0.5$ and thus $\rho^{*}=0.675$. Whenever the selected fuel tax is lower than 0.5 , country A can benefit from selecting a fuel tax equal to the external $\operatorname{cost}\left(t_{A}=4\right)$ and thus foregoing largely the revenues of fuel sales from international trucking. When international truck traffic is less important $(D=5)$, revenues from fueling international trucks are also less important and the critical values become
} $t^{*}=0.95$ and $\rho *=0.42$. 
Why can this critical fuel tax rate $t^{*}$ not be a Nash equilibrium? In a symmetric equilibrium and for a set of parameter values that imply intense tax competition $\rho \geq \rho^{*}$, the Nash equilibrium as defined by PROP 2 implies such low fuel tax rates that each of the two countries can achieve the same level of welfare or higher by foregoing the international trucking fuel sales and charging the local trucks a much higher fuel tax that matches the external cost $e c$. This generates a discontinuity in the reaction functions of both countries. Let's continue our reasoning and imagine that country A abandons the low fuel tax and charges the external cost. Country B's best reply is to increase its fuel tax to just below the high fuel tax level in A. But then A finds it profitable again to charge slightly less than B etc. As illustrated here, reaction functions are discontinuous at very low tax rates and no Nash equilibrium in pure strategies exists. In our numerical illustration for Germany (section 7) we show that the non-existence case is rather a theoretical curiosum at the level of countries. The extreme tax competition problem could explain why we don't see fuel taxes decided noncooperatively at the level of two neighboring cities.

In a symmetric equilibrium, and given our assumptions, any fuel tax that is different from the external cost is inefficient for both countries. The driver of this inefficiency is the tax competition incentive. The following two figures help to convey the intuition for the symmetric case:

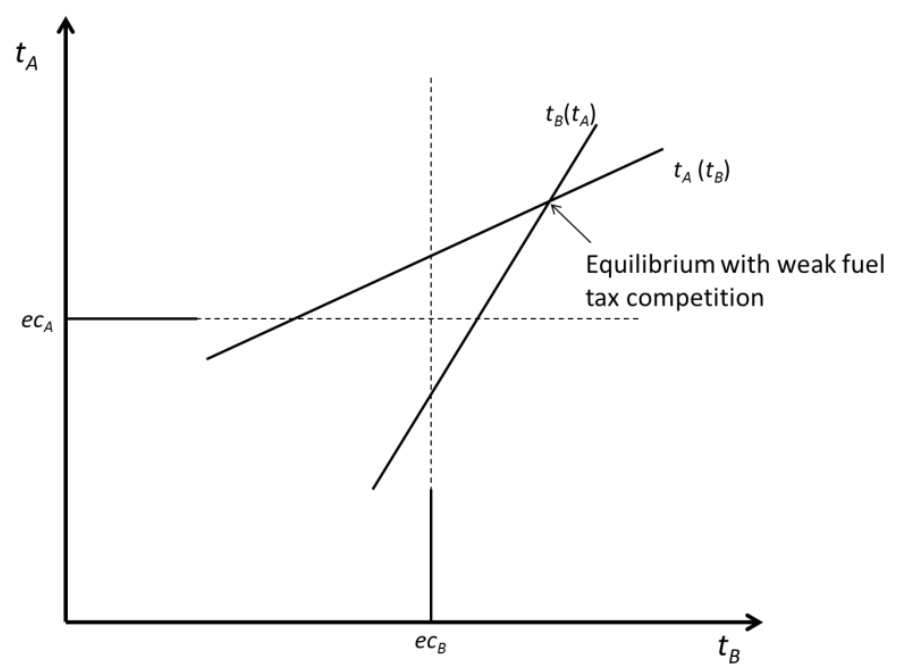

Figure 4, Equilibrium with weak fuel tax competition

To see the intuition of Figure 4, assume first that country $B$ is charging the external cost, so that country $A$ will find it profitable to have a fuel tax somewhat larger than the external cost since tax competition is relatively weak. Foreign haulers pay extra taxes while the cost to local haulers is of a second order: only the deadweight loss counts since the higher taxes paid are a 
pure transfer. The fuel tax will be above the external cost but both the tax competition and the deadweight loss to locals will ultimately limit the fuel tax, even if the tax competition is weak.

We can also have a Nash equilibrium with very strong tax competition as long as $\rho<\rho^{*}$. This could be the case for smaller countries where there is relatively more international traffic and where the international fuel market share is very price-sensitive ( $\rho$ large in (4)). This is illustrated in Figure 5 . To see the intuition assume again that country $B$ charges the external cost. Then it becomes profitable for country $A$ to undercut country $B$ as it can make international trucks buy fuel in country $A$. With a fuel tax lower than the external cost, the cost for country $A$ is the additional volume of local truck activity in country $A$ that is not paying the full external cost, while the gain is the international haulers buying fuel for their trips in both country $A$ and country $B$. For the trips in $B$, country $A$ does not bear the external costs. If the fuel price competition intensity becomes larger, the reaction functions do not cross each other anymore in Figure 5 and a Nash equilibrium in pure strategies no longer exists.

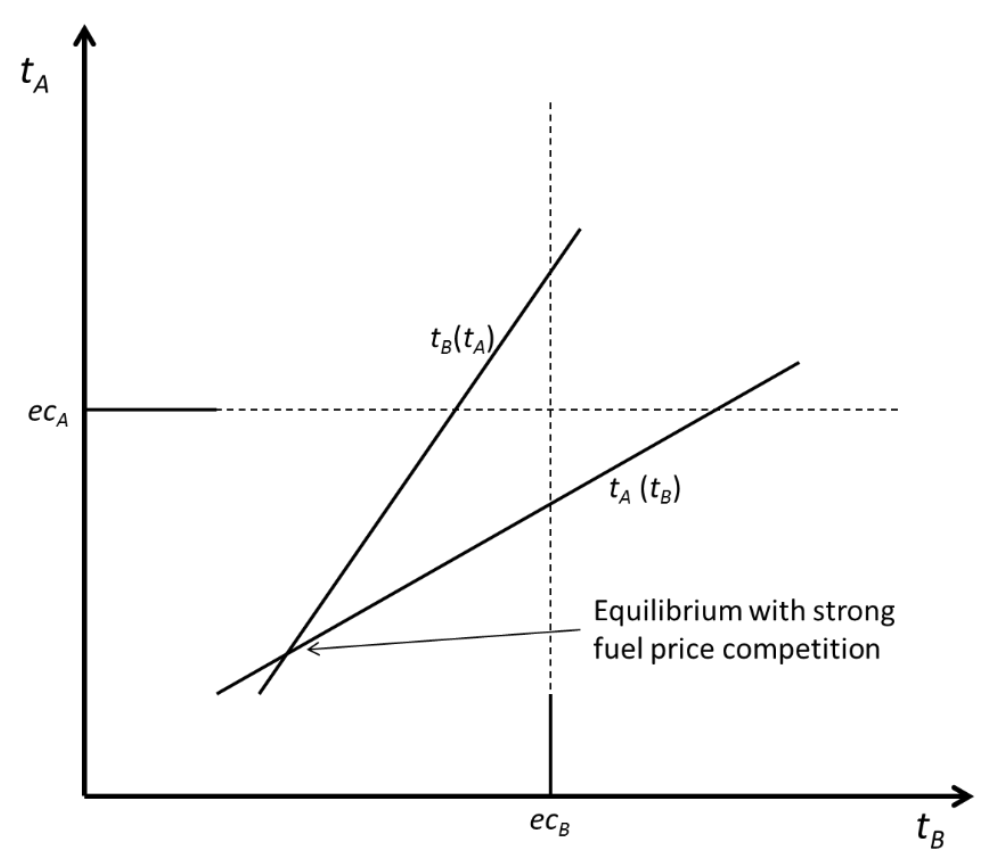

Figure 5, Equilibrium with intensive fuel tax competition.

Thus, the fuel tax equilibrium, if it exists, is able to generate too high as well as too low fuel taxes compared to external costs. Both cases thus involve inefficient pricing due to tax competition. 
Asymmetric fuel tax equilibrium with price-dependent domestic truck demand

Thus far, we have focused on the asymmetric case with fixed demand (PROP 1) and on the symmetric case with price-dependent truck demand (PROP 2). PROP 1 was a simpler case because with fixed demand, external costs play no role. In PROP 2 both counties were fully symmetric. We now relax both assumptions and come to the following result:

PROP 3 When domestic and international truck demand are price-dependent and fuel tax competition is low $\rho<\rho^{*}$, a non-symmetric Nash equilibrium where only fuel taxes are available to charge trucks is as follows:

Either $\boldsymbol{t}_{\boldsymbol{A}}>>\boldsymbol{t}_{\boldsymbol{B}}$ leading to $t_{A}=e c_{A}$

Or $\boldsymbol{t}_{\boldsymbol{A}}<<\mathbf{t}_{\boldsymbol{B}}$ leading to $t_{A}=\left(1-\frac{\frac{\partial D}{\partial t_{A}}(1-\gamma)}{\frac{\partial D}{\partial t_{A}}+\gamma \frac{\partial d_{A}}{\partial t_{A}}}\right) e c_{A}+\frac{-0.5}{\frac{\partial D}{\partial t_{A}}+\gamma \frac{\partial d_{A}}{\partial t_{A}}} D>e c_{A}$ and $t_{B}=e c_{B}$

Or (when international traffic $D$ is kept fixed):

$$
\begin{aligned}
& t_{A}=e c_{A}-\frac{D}{\frac{\partial d_{A}}{\partial t_{A}}}-\frac{\rho D}{\gamma \frac{\partial d_{A}}{\partial t_{A}}} t_{B} \\
& t_{B}=e c_{B}-\frac{D}{\frac{\partial d_{B}}{\partial t_{B}}}-\frac{\rho D}{(1-\gamma) \frac{\partial d_{B}}{\partial t_{B}}} t_{A}
\end{aligned}
$$

PROP 3 shows that several equilibriums are possible when countries differ in size and external costs. When would country $A$ (by assumption larger in size than $B$ ) go for a particular equilibrium?

Charging the external cost $\left(t_{A}>>t_{B}\right.$ and $\left.t_{A}=e c_{A}\right)$ may result in a Nash Equilibrium when the external cost in $A$ is much higher than in country $B$ and there is no strong tax competition. In that case, for country $A$ it is not interesting to go for much lower fuel taxes as it would strongly distort its domestic traffic with no tax revenue gain.

Charging much less than the other country $\left(t_{A}<<t_{B}\right.$ and $\left.t_{A}>e c_{A}\right)$ can be an equilibrium when the external cost in $A$ is much lower than in country $B$. In that case, $A$ will increase the tax above its external cost in order to charge a monopoly margin, with the only restraint being the distortion on the domestic trucking market. 
Finally, the equilibrium may consist of fuel taxes under which both countries have a positive share in the fuel sales to international trucks. In this case taxes can be higher or lower than the external cost. One of the important elements is size. Figure 6 presents the equilibrium with fuel taxes only. Because $B$ is a smaller country it can gain high revenues from international haulage by setting a low fuel tax. The reason is that undercutting gives the small country access to a much larger tax base, while for the big country the home market remains proportionally more important. This result is in line with Kanbur and Keen (1993), but note that the setting is different for Kanbur and Keen because, in our model, governments are not Leviathan and external costs and consumer surpluses count. ${ }^{14}$

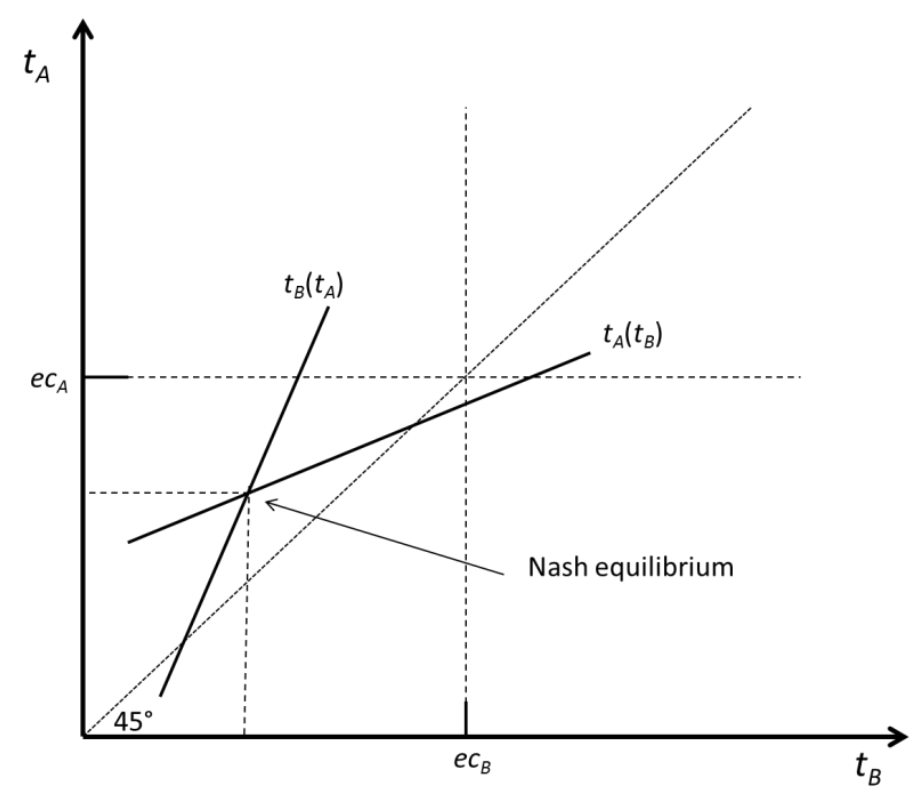

Figure 6, Equilibrium with fuel taxes only when $B$ is smaller country, $t_{A}>t_{B}$

\section{Adding distance charges as a policy instrument in the absence of diesel cars}

Thus far, we have addressed the implications of strategic interaction between governments on fuel taxes. However, the main subject of interest in this paper is how countries react when a distance charge becomes possible. In particular, we are interested in how the introduction

\footnotetext{
${ }^{14}$ If we compare the tax in our setting, from equation (9), with that under a Leviathan government, two opposing effects are present; (i) as the Leviathan government does not care about the consumer surplus it will impose a higher tax in order to gain additional revenue from both domestic and international transport and (ii) the Leviathan government does not care about the external cost. Effect (i) calls for a strictly larger tax than in our setting. However, this may be outweighed if the external cost is large enough from effect (ii).
} 
of distance charges changes the governments' choice in fuel taxes and how the underlying mechanisms work.

To examine this, we start again from the objective function (6) of the country $A$ government and derive first order conditions for $t_{A}$ and $T_{A}$. The first order condition for the fuel tax in $A$, conditional on its distance charge, then becomes:

$$
\begin{gathered}
-\gamma d_{A}+\gamma \frac{\partial d_{A}}{\partial t_{A}}\left(t_{A}+T_{A}-e c_{A}\right)+\gamma d_{A}-0.5 D \frac{\partial G_{A}}{\partial t_{A}}+\frac{\partial D}{\partial t_{A}}\left(\sigma t_{A}+\gamma T_{A}-\gamma e c_{A}\right)+\frac{\partial \sigma}{\partial t_{A}} D t_{A}+\sigma D \\
=0
\end{gathered}
$$

Similarly, the first order condition for the distance charge, $T_{A}$, is given by:

$$
-\gamma d_{A}+\gamma \frac{\partial d_{A}}{\partial T_{A}}\left(t_{A}+T_{A}-e c_{A}\right)+\gamma d_{A}-0.5 D \frac{\partial G_{A}}{\partial T_{A}}+\frac{\partial D}{\partial T_{A}}\left(\sigma t_{A}+\gamma T_{A}-\gamma e c_{A}\right)+\gamma D=0
$$

PROP 4 Assume distance charges may be used and that there are other tax instruments for diesel cars; then if a Nash equilibrium exists in pure strategies, it cannot involve diesel fuel taxes and $0<\sigma<1$. The equilibrium distance charges are greater than the marginal external cost:

$t_{A}=t_{B}=0$

$$
T_{A}-e c_{A}=\frac{0.5 D}{\gamma(b+\beta)}>0
$$

$T_{B}-e c_{B}=\frac{0.5 D}{(1-\gamma)(b+\beta)}>0$

PROOF: See Appendix 5

Before showing the intuition behind this result, consider the equilibrium values of distance charges in the absence of fuel taxes. The distance charges will be larger than the external costs, and the mark-up on top of the external cost will be larger in small countries as they have more revenue to gain from international trips. In addition, the mark-up in the distance charges will be smaller when domestic truck trips are very price-sensitive and/or more important.

We can show the intuition behind the dominance outcome for distance charges using a thought experiment. Consider the effects of introducing a distance tax when a fuel tax is already present. Starting from Figure 4 we construct Figure 7. Initially, there are only fuel 23 
taxes. Next we consider the gradual substitution of the initial equilibrium with fuel tax $t_{A}{ }^{\circ}$ by a combination of a smaller $t_{A}$ and a small positive $T_{A}$ while retaining the same sum $t_{A}+T_{A}=$ $t_{A}{ }^{\circ}$ and the same $t_{B}{ }^{\circ}$. Note that this substitution will not affect local traffic as it is only influenced by the sum of the two taxes. ${ }^{15}$ The main effect will be larger tax revenues in country $A$. The major difference is a larger market share on the fuel market: country $A$ 's revenues will increase. We did not alter the reaction function of country $B$, although this can change slightly since it is also a function of the level of $T_{A}$. The initial fuel tax in country $B\left(t_{B}\right)$ is no longer the best response for country $B$ so there will be a shift to a new equilibrium with increasingly lower fuel taxes in both countries.

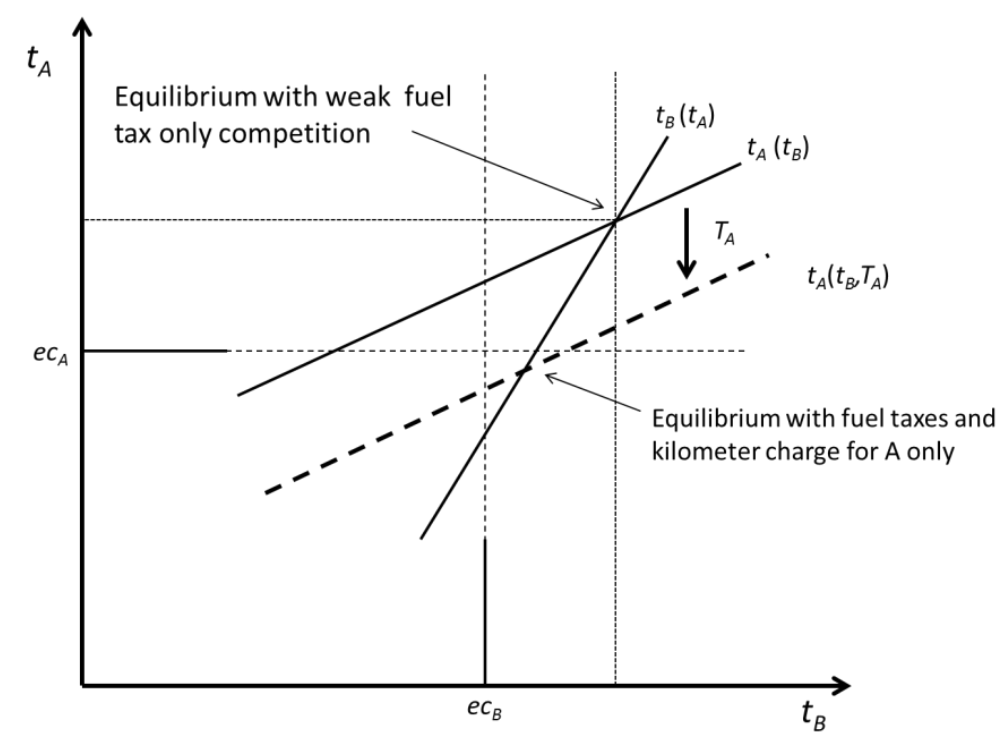

Figure 7, Equilibrium when country A also uses a distance charge tax but country $B$ only makes use of a fuel tax.

The total tax for the use of the road in country $A$ may increase strongly as the kilometer tax allows $A$ to better charge for the external cost and to raise revenue on international traffic.

\footnotetext{
${ }^{15}$ If we allow the tax to influence the volume of international transport demand, the substitution will generate a small increase in international haulage as haulers will benefit from lower fuel taxes in country $A$ and $B$, which compensates the increase in $T_{A}$. There will be an additional external cost in both countries but this is undoubtedly covered in country $A$ by the sum of the two taxes.
} 
Let us start from another extreme equilibrium where both countries initially only use a kilometer charge. This equilibrium is one of the serial network type where both countries tax the same base (international traffic), which gives an equilibrium where distance charges are larger than the external cost (De Borger, Dunkerley, Proost, 2007). The reason is that part of the tax base of each country is foreign and will always be taxed above the external cost. If we allow for elastic international transport demand, the reaction function $T_{A}\left(T_{B}\right)$ will be downward sloping because every increase in the kilometer charge in the other country will decrease the international haulage volume, and for this reason, the optimal distance charge will also decrease. Now, will one of the countries gain by re-introducing a fuel tax?

Consider Figure 8 where we start from an equilibrium $\left(T_{A}^{\circ}, T^{\circ}{ }_{B}\right)$ where only distance charges can be used and the fuel tax instrument is not used. This is illustrated by the intersection of the two solid lines. Consider now a substitution of part of $T_{A}$ by a fuel tax in country $A$. This corresponds to the dotted line parallel to the reaction function of country $A$. Clearly, country $A$ cannot gain from such a substitution. For local traffic it will not make a difference, but international traffic will buy fuel in country $B$ where it is not taxed, so that country $A$ will lose part of the revenue that it hoped to collect with the fuel tax.

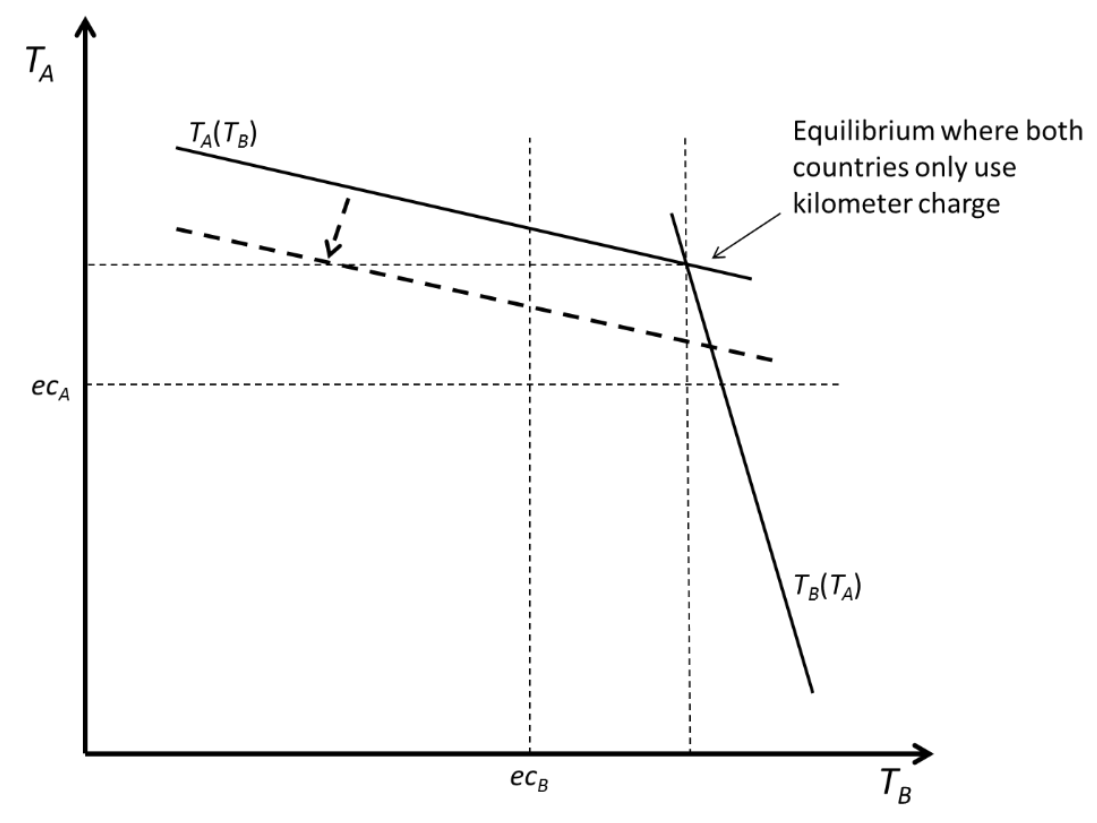

\section{Figure 8, Equilibrium with only kilometer charges}

Thus in equilibrium, when both countries can freely choose fuel tax levels and distance charges, they will both prefer a distance charge that is above the external cost while the fuel tax is driven to 0 . 
PROP 5 (conjecture) When there are other tax instruments for diesel cars, the option to introduce distance charges for trucks may be welfare decreasing in symmetric equilibrium

When we move from a fuel tax only system to a distance charge system, there are two differences. First there is the difference in implementation costs, where one can reckon that distance charges are more costly than fuel taxes. Second, distance charges are always larger than the external cost while the deviation between the external cost and the fuel tax can be lower or higher than in the case of the distance charge. The technology for distance charges will likely improve such that it allows for better differentiation by vehicle type (weight, environmental impact, etc.) as well as by time and place. Then, the charge may become much more efficient; however, this is not the type of distance charge we consider here.

It is obvious that the large country can benefit from introducing a kilometer charge in order to escape the downward pressure on its fuel tax level from the small country. For the small country, however, the costs and benefits of the kilometer charge are less obvious as it is able to extract revenue from foreign international traffic in both systems.

Consider the case where only kilometer charges are used by countries that are different in size. This is represented in Figure 9. The solid lines in the figure illustrate the symmetric case, where the countries are of equal size. Consequently, the Nash equilibrium entails $T_{A}=$ $T_{B}$ and thus lies on the 45 degree line. Now consider the case where country $B$ is smaller than A. The reaction function of $B$, the dashed line in Figure 9, lies above the corresponding reaction function in the symmetric case.

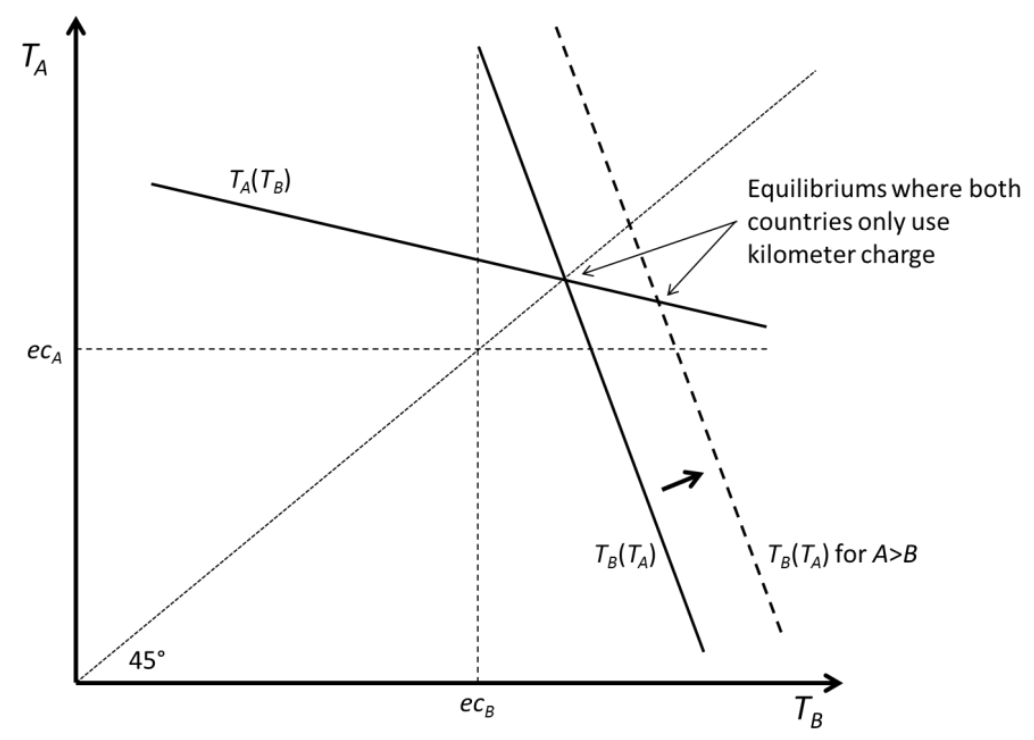

Figure 9, Equilibrium with kilometer charges only 
As seen in Figure 9, the distance charge will be higher in the smaller country. This is because country B has proportionally more foreign traffic on its roads and thus can benefit by charging more per kilometer. This is the reverse case of fuel taxes, where the smaller country undercuts the fuel tax of its large neighbor.

\section{Numerical illustration}

This section provides a numerical illustration of our analytical results. We use Germany as a base for the calibration, but strive only to get the orders of magnitude correct.

The total amount of goods transportation by road in Germany in 2012 amounted to around 307000 million tonkm. Out of these, $20 \%$ was international transports (Eurostat ${ }^{16}$ ). We assume the cost of truck transport to be 35 euro per 1000 tonkm, out of which $20 \%$ stems from fuel costs, taken as the average in EU8. We employ a fuel price elasticity of 0.25 (based on De Jong et al., 2010). This is the basis for the calibration of linear demand functions for domestic and international truck transport ${ }^{17}$.

The external cost is set at 3 euro per 1000 tonkm (0.06 euro per vehiclekm, 20 ton per vehicle - computed from (European Commission, (2014)). We use these values to represent both countries. That is, we let two identical Germanys compete with each other, giving the fuel taxes and distance charges exhibited in table 1 for the case of low $(\rho=0.05)$ and high $(\rho=0.5)$ tax competition, respectively.

Table 1 Fuel taxes and distance charges in the Nash equilibrium when there are no diesel cars*

\begin{tabular}{llll|llll} 
& \multicolumn{2}{l}{$\rho=0.05$} & \multicolumn{3}{l}{$\rho=0.5$} \\
\cline { 2 - 6 } & $t_{A}=t_{B}$ & $T_{A}=T_{B}$ & $W_{A}$ & $t_{A}=t_{B}$ & $T_{A}=T_{B}$ & $W_{A}$ \\
\hline Fuel tax only, fixed demand & 5 & - & & 0.5 & - &
\end{tabular}

16

http://epp.eurostat.ec.europa.eu/statistics_explained/index.php?title=File:National_and_international_r oad_transport_of_goods,_2012_(1)_(\%25_based_on_million_tkm_of_laden_transport)_YB14.png\&fil etimestamp $=20140311101514$

${ }^{17}$ For the domestic demand, we set $\mathrm{a}=552$ and $\mathrm{b}=8.8$ and for the international demand we set $\alpha=$ 138 and $\beta=2.2$. Given a total cost, including taxes, of 35 euro per 1000 tonkm, these assumptions yield a domestic annual transport of 244 billion tonkm and an international volume of 61 billion tonkm (to be compared to the actual values of 246 and 61, respectively, in 2012). 


\begin{tabular}{llll|lll} 
Fuel tax only & 4.1 & - & 781 & 0.67 & - & 775 \\
Fuel tax and distance charges & 0 & 8.29 & 737 & 0 & 8.29 & 737 \\
\hline & $t_{A} ; t_{B}$ & $T_{A} ; T_{B}$ & $W_{A}$ & $t_{A} ; t_{B}$ & $T_{A} ; T_{B}$ & $W_{A}$ \\
\hline Trucks only, $t_{B}=e c$ and $T_{B}=\mathrm{O}$ & $0 ; 3$ & $8.85 ; 0$ & 851 & $2 ; 3$ & $6.50 ; 0$ & 918 \\
Trucks only, $T_{B}=0$ & $0: 4.19$ & $8.82 ; 0$ & 844 & $0 ; 0.64$ & $9.02 ; 0$ & 888 \\
\hline
\end{tabular}

${ }^{*} t_{\mathrm{A}}, \mathrm{t}_{\mathrm{B}}, \mathrm{T}_{\mathrm{A}}, \mathrm{T}_{\mathrm{B}}$ in Euro/ 1000 tonkm and $\mathrm{W}_{\mathrm{A}}$ in million Euro per year.

Both the fuel tax and the distance charge in Table 1 are expressed in Euro per 1000 tonkm. The first row in table 1 exhibits the case of totally inelastic demand for international freight transport. As expected from PROP 1, the fuel tax is higher when tax competition is less intense ( $\rho=0.05$ rather than 0.5 ). The second row allows for elastic international demand, which in effect implies that the consumer surplus of international trucks, the external cost as well as the share in international total revenues, become more important when setting the fuel tax. The result is that the fuel tax is reduced in the low tax competition case $(\rho=0.05)$, but it is still higher than the external cost $(e c=3)$. The Nash equilibrium tax is substantially lower in the strong tax competition case, $t=0.67$, but it is higher than in the inelastic case because a higher tax allows for a decrease in the external costs of trucking. Diesel excise taxes in the EU expressed as Euro per 1000 tonkm, as in Table 1, are more likely to be approximately 5 or slightly higher, rather than 0.5 . This suggests that the actual case is better captured by the lower tax competition case ( $\rho=0.05)$ than by the stronger case $(\rho=0.5)$ and that moreover, we are far from the regime where the Nash equilibrium would no longer exist.

The third row introduces distance charges as an additional instrument. The findings in Prop 4 are clearly visible, the fuel tax in both countries is zero, and the distance charge is set far above the external cost. It is worth noting that the distance charge is the same in both the weak and strong tax competition case. This is not surprising as the tax competition only operates through fuel taxes, which are driven to the bottom for this very reason. Thus, given the assumption of 20 ton per vehicle, a distance charge of 8.29 corresponds to $€$ o.166 per vehicle kilometer. This is in line with the current charge on the German network of $€ 0.158$ per vehicle kilometer (Vierth et al., 2015), but one must note that Germany also applies a fuel tax since it has diesel cars. The total tax on trucks in Germany is thus in reality higher than what is suggested by Table 1 .

The lower part of table 1 illustrates the mechanism when country B's response is restricted. In the first of these rows, country B is not able to use a distance charge and is also restricted to applying a fuel tax equal to the external cost. In the weak competition case, country A will then apply a high distance charge and a zero fuel tax. In the strong competition case we end up in a corner solution where A sets a fuel tax equal to 2, which will capture the entire 
international fuel market; A sets the distance charge such that the sum of the fuel tax and distance charge is close to what we find in the weak competition case.

The last row illustrates the more realistic case where $B$ is not yet able to implement a distance charge, but will respond to A's policy by optimizing its fuel tax. Both in the weak and strong competition case, country A will implement a distance charge substantially above the external cost. B's best response is highly dependent on the level of tax competition. When tax competition is weak, B will set a fuel tax above the external cost. However, when tax competition is strong, $\mathrm{B}$ is forced to set a fuel tax far below the external cost. In all cases, A will only use distance charges in optimum.

$W_{A}$ in table 1 is a measure of the welfare (in million Euro) in country A calculated, using (6), in the absence of transaction and implementation costs. This is what country A strives to maximize when it decides on taxes and charges. The exact number is of little interest as it strongly depends on the assumption of linear demand. Comparing this value for the different cases however yields several interesting observations. First, note that $W_{A}$ is lower in the third row than in the second row. As these cases are symmetric, the same applies for the welfare in B. Thus, in this particular setting, welfare decreases when both countries introduce distance charges as we conjectured in PROP 5.

This is a surprising result, because if introducing distance charges would decrease welfare, why do it? The answer is evident from the second part of table 1, where country B is restricted to using fuel taxes only. There we see that the welfare increase in A from introducing a distance charge - given that B does not follow - is large. This is particularly so if country B cannot even optimize its fuel tax. In that case country A will capture the entire fuel market and also charge international transport for the distance driven. In the last case, where $\mathrm{B}$ optimizes its fuel tax, the welfare in B will be 676 (weak competition) and 633 (strong), respectively ${ }^{19}$.

Table 2 highlights the prisoner's dilemma structure that is embedded in Table 1. The numbers refer to the strong tax competition case, but a similar situation is apparent under weak competition. The only Nash equilibrium exists when both countries employ both

\footnotetext{
${ }^{19}$ The welfare in B will of course be even less when it cannot optimize its fuel tax -510 (weak) and 610 (strong), respectively.
} 
instruments ${ }^{20}$, in which case the welfare is less than it would in the case where both countries would use fuel taxes only. This implies that using both instruments is a dominant strategy, even though both countries would be better off sticking to only fuel taxes.

Table 2, Welfare for each policy combination displayed as a normal form game

\begin{tabular}{lll|l|}
\multicolumn{5}{c}{} & \multicolumn{2}{l}{$\begin{array}{l}\text { Country B } \\
\text { Fuel tax only }\end{array}$} & Both instruments \\
\cline { 3 - 4 } Country A & Fuel tax only & $(775 ; 775)$ & $(633 ; 888)$ \\
\cline { 2 - 4 } & Both instruments & $(888 ; 633)$ & $(737 ; 737)$ \\
\cline { 3 - 4 } & &
\end{tabular}

The Prisoner's dilemma structure we find here is in line with earlier literature on the choice of pricing instruments by firms. Thisse and Vives (1988) study a market with competing firms that may choose between a uniform pricing strategy and a spatial price discrimination strategy. They show that spatial price discrimination is a dominating strategy, but that it reduces profit compared to uniform pricing. To translate this into our model, fuel taxes can be seen as the uniform pricing strategy and distance charges as a way to achieve spatial price discrimination and end up with lower welfare. Closely related, Corts (1998) shows that firms may prefer inflexible price technologies in order to avoid price competition.

\section{An extension - transit countries}

This paper has analyzed a stylized case of two countries and often restricted attention to the symmetric case. Reality offers many interesting special cases, some of which can be discussed using our framework. Consider again Switzerland, Austria and Luxemburg, which were special due to geography (cfr. map in Annex 1).

Switzerland is a transit traffic country that holds a strategic position in between Germany and Italy. Our two-country model is not designed to study the case of transit countries. However, we can easily reformulate the government objective function (7) so that it comes close to the Swiss case. When international traffic is mainly transit traffic like in Switzerland, a country is not interested in the consumer surplus of international traffic but does want to maximize its tax revenues.

We can extend the two country model to include Switzerland by assuming that an international truck trip consists of a distance $\gamma$ in Germany, a distance $\omega$ in Switzerland and a

\footnotetext{
${ }^{20}$ Actually, only distance charges are used in the "both instruments" case as both countries apply a fuel tax of zero in equilibrium.
} 
distance $(1-\gamma-\omega)$ in Italy. Switzerland is not interested in half of the consumer surplus of the international trips as all international trips are by definition international trips between Germany and Italy. This allows us to derive the following optimal distance charge for Switzerland $\mathrm{T}_{\mathrm{S}}$, for Germany $\mathrm{T}_{\mathrm{G}}$ and Italy $\mathrm{T}_{\mathrm{I}}$ (assuming fuel tax=0 and following the procedure used in section 6):

$$
\begin{aligned}
T_{S}-e c_{S} & =\frac{D}{\omega(b+\beta)} \\
T_{G}-e c_{G} & =\frac{0.5 D}{\gamma(b+\beta)} \\
T_{I}-e c_{I} & =\frac{0.5 D}{(1-\gamma-\omega)(b+\beta)}
\end{aligned}
$$

This will lead to very high distance charges in Switzerland: comparing the charges of Switzerland and Germany, we have:

$$
\frac{T_{S}-e c_{S}}{T_{G}-e c_{G}}=2 \frac{\gamma}{\omega}
$$

As Switzerland is usually a smaller part of the total trip $(\omega<\gamma<1)$, Switzerland could charge an extra margin, on top of the external cost, that is much larger than Germany. This is in line with what we observe in Figure 1. The Swiss distance charge is at least three times as large as in Germany. Note that Switzerland charges in reality a high diesel excise to tax its diesel cars as the distance charge generates more than enough revenues on international trucks.

The model could be further extended to include a parallel transit country. This would then add a duopoly structure for the pricing by transit countries. The presence of good transit alternatives would drive down distance charges and fuel prices in the transit countries. Our proposition 4 that distance charges are the dominant instrument would continue to hold. The formal extension of our framework would need an additional transit market sharing parameter $\xi\left(T_{1}, t_{1}, T_{2}, t_{2}, t_{A}, t_{B}\right)$ for the two parallel transit countries $(1,2)$. The choice of transit country would then depend on the relative distance charges as well as the relative fuel taxes in both the transit countries and in the countries of origin and destination. As this would not add new insights and makes the model more complex to solve (competition with 8 tax instruments), we leave the full model solution for an applied paper. However, a formal model is not necessary to discuss the pricing strategies of Austria and Luxemburg.

The best alternative for Switzerland is to pass through Austria, but it is often an inferior alternative. Austria was the first (along with Germany) to follow the example of Switzerland 31 
by implementing a distance-charging scheme. As Austria is part of the EU, it must adhere to the cap on distance charges: charges cannot exceed the average infrastructure and air pollution costs. However, there is a provision in the EU-directive on distance charges that allows "mountainous areas" to charge more. The result is that the sum of the Austrian distance charge + fuel tax is higher than in other EU countries but is only one third of the sum of the Swiss charge + fuel tax (cfr. Figure 1). Note that Austria uses a higher distance charge but a lower fuel tax than Germany and in this way maximizes its revenues from the international fuel market.

For Luxemburg it is the other way around: a truck can easily avoid passing through Luxemburg, therefore this country is not interested in distance charges; instead, it has used the strategy of undercutting the fuel taxes of its neighbors and has blocked many EU proposals to increase the minimum excise rates on motor fuels. This strategy is now at risk. Paradoxically, now that its neighbors are adopting distance charges, Luxemburg may soon plead for minimum fuel excises for diesel in order to protect its revenue base.

\section{Introducing diesel cars}

Thus far, we have shown that both countries face incentives to implement distance charges and set fuel taxes to zero. However, this is not what we see in reality. Several countries within the EU have adopted distance charges, but none have abandoned fuel taxes after doing this. There may be several reasons for this. One such, and arguably very important, is that it is not only trucks but also cars that use diesel. In this concluding analytical section of the paper, we extend the model to also take this into consideration.

Completing the model by adding diesel cars

Assuming that the gasoline fuel tax on cars is fixed and that there is no other tax on diesel cars other than the diesel fuel excise, it is necessary to adapt the model. This is in order to take into account the consumer surplus of diesel car users and the possible side effects of diesel taxes on the gasoline car market. We assume that cars do not fuel up abroad and that the gasoline tax is fixed. In order to complete the model, we must add a demand function for both diesel and gasoline cars. Let the demand functions for diesel and gasoline cars be:

$$
\begin{gathered}
x_{A}^{d}=a-b_{A}^{d} g_{A}^{d}+\varsigma\left(c^{g}+t_{A}^{g}\right) \\
x_{A}^{g}=a-b_{A}^{g} g_{A}^{g}+\psi\left(c^{d}+\theta^{d} t_{A}\right)
\end{gathered}
$$


In this formulation, superscript $d$ and $g$ denote diesel cars and gasoline cars respectively, $x$ represents the mileage of cars, and $g$ represents the generalized cost per trip. The generalized driving costs are equal to

$$
\begin{gathered}
g_{A}^{d}=\gamma\left(c^{d}+\theta^{d} t_{A}\right) \\
g_{A}^{g}=\gamma\left(c^{g}+t_{A}^{g}\right)
\end{gathered}
$$

Where $\theta^{d}$ represents the relative consumption of fuel per mile by a diesel car compared to a diesel truck. Remember that $t_{A}$ represents fuel tax paid per mile for a truck. So $\theta^{d}$ is typically $1 / 4$ or less. This matters since the same fuel tax has to price both the external costs of a truck and the external costs of a car. When $t_{A}=e c$ there is no guarantee that $\theta^{d} t_{A}=e c^{d}$.

Next we must add three terms to the objective function (6): the consumer surplus of the local diesel car user $\left(c s^{d}\right)$ as well as the fuel tax revenues and external costs for diesel and gasoline cars. Let $e c^{d}$ and $e c^{g}$ be the external costs per mile of diesel and gasoline cars:

$$
\begin{aligned}
& c s_{A}\left\{g_{A}\{.\}\right\}+d_{A}\{.\}\left(\gamma t_{A}+\gamma T_{A}-\gamma e c_{A}\right)+0.5 \operatorname{CS}\{G\{.\}\}+D\{.\}\left(\sigma t_{A}+\gamma T_{A}-\gamma e c_{A}\right)-I T_{A}+ \\
& \operatorname{cs}_{A}^{d}\left\{g_{A}^{d}, g_{A}^{g}\right\}+x_{A}^{d}\left(\gamma \theta^{d} t_{A}-\gamma e c_{A}^{d}\right)+x_{A}^{g}\left(\gamma t_{A}^{g}-\gamma e c_{A}^{g}\right)
\end{aligned}
$$

When the fuel tax is the only instrument to tax diesel cars and diesel trucks If a symmetric Nash equilibrium in fuel taxes exists, we obtain the following fuel tax:

$$
t_{A}=t_{B}=\frac{\beta \gamma^{2}+b \gamma}{\varphi} e c_{A}+\frac{\gamma \theta^{d} b^{d}}{\varphi} e c^{d}+\frac{\gamma^{2}}{\varphi} D+\frac{\partial x_{A}^{g}}{\partial t_{A}^{d}}\left(\frac{\gamma t_{A}^{g}-e c_{A}^{g}}{\varphi}\right)
$$

Where $\varphi=\beta \gamma^{2}+b \gamma+\rho D+\theta^{d} b^{d}$

We see that the diesel fuel tax now brings four elements on board. The external and infrastructure cost for trucks (1st term) and the revenue-raising term for international truck transport $\left(3^{\text {rd }}\right.$ term) were already discussed before. The new ones are the $2^{\text {nd }}$ term, representing the external cost of diesel car use, and the $4^{\text {th }}$ term, representing the effect of diesel tax changes on the distortion of the gasoline market. If the gasoline tax can be set optimally, the last term disappears. The diesel tax is then one instrument that is used to correct the external costs of two very different vehicles (cars and trucks) as well as to try to raise revenues from international transport. The externality correction objectives receive relatively more weight when domestic car and truck demand become more price-sensitive. The revenue-raising objective receives less weight when competition for international fuel sales is fierce (high $\rho$ ). 
Introducing distance charges into the symmetric equilibrium

In the absence of diesel cars, introducing distance charges leads to an equilibrium where fuel taxes are driven to 0 . When diesel cars can only be taxed using fuel taxes, using zero fuel taxes is not a candidate equilibrium since diesel cars would escape these. So we need a complex balance of the fuel tax as an externality tax for diesel cars and as a revenue-raising tax on international trucking. We proceed in two steps. First we intuitively explore the symmetric equilibrium and next discuss possible generalizations of the intuitive results. The easiest situation to start with is one where the fuel taxes are set equal to the external cost of a diesel car, the gasoline tax is equal to the external cost of a gasoline car, and the distance charges internalize the external costs from freight transport that are not handled by the diesel tax. This is represented in Figure 10 as $\theta^{d} t^{\circ}=e c^{d}$ and $T^{\circ}+t^{\circ}=e c$ but this tax level cannot be an equilibrium. The reason is that international trucks can still decide where to buy fuel. Whenever there is a diesel tax, there are opportunities for each government to increase their fuel tax revenues on the international fuel market for trucks by decreasing the fuel tax slightly. Also, there are incentives to increase the distance charge above the external cost, accounting for the diesel tax, as this increases tax revenues but only partially hurts domestic haulers. Consequently, in equilibrium, $\theta^{d} t^{*}<e c^{d}$ and $T^{*}+t^{*}>e c$. That is, the fuel tax will be below the external cost of diesel cars, but the sum of the distance charge and the fuel tax for trucks will be larger than the external costs of trucks.

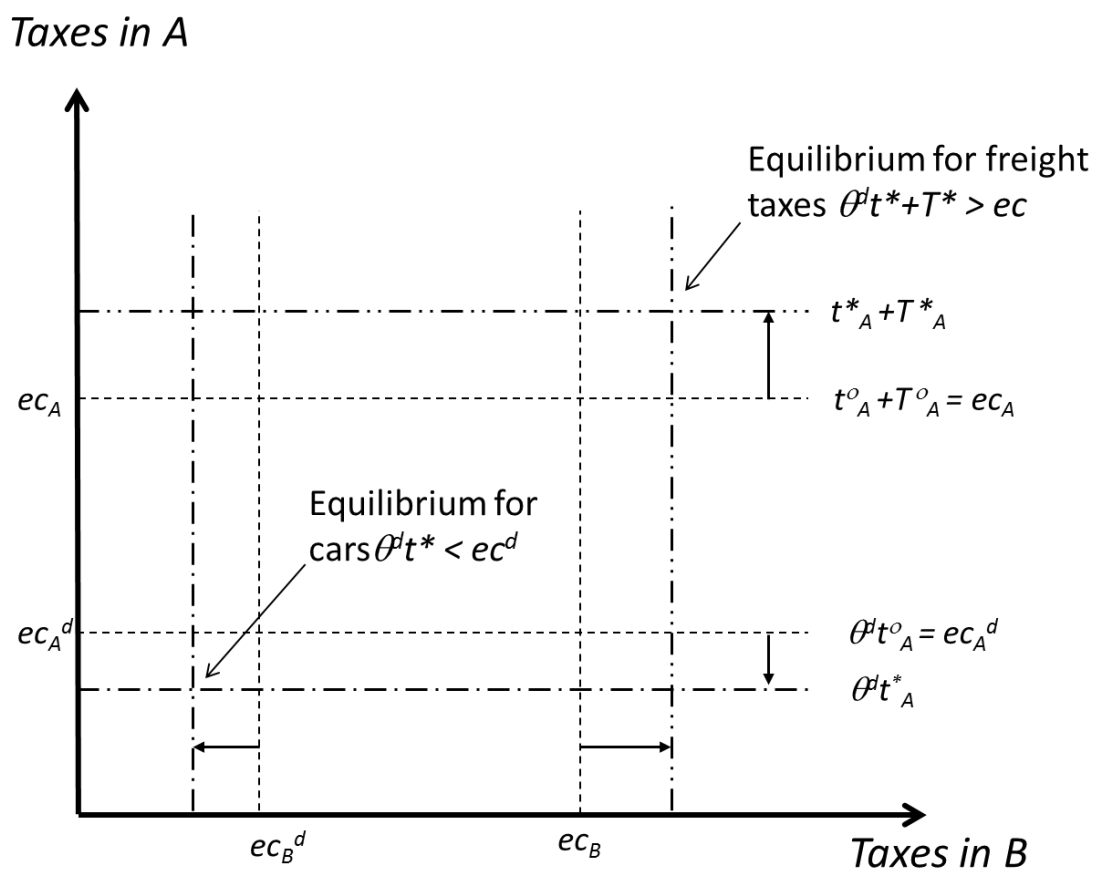




\section{Figure 10, Equilibrium with distance charges and fuel taxes in the presence of diesel cars}

We can discuss the introduction of distance charges in the presence of diesel cars more formally. Assuming that the gasoline tax equals the external cost of gasoline cars, we need to analyze two possible initial equilibria in the situation where only fuel taxes can be used.

In the first case the diesel tax charged is larger than the external cost of a diesel car:

$$
\theta^{d} t_{A}^{o}-e c_{A}^{d}>0
$$

which will be the case when diesel cars are rather clean and there is less of a tax competition for truck fuel. In this case, a substitution of diesel taxes by distance charges $d T_{A}=-d t_{A}>0$, starting from $t_{A}, t_{B}>0$ and $0<\sigma<1$, is even more beneficial for country A than in the absence of diesel cars, since the pricing distortion on diesel cars decreases on top of the net revenue gain. So whenever $\theta^{d} t_{A}^{o}-e c_{A}^{d}>0$, this cannot be a Nash equilibrium.

Consider next the case where $\theta^{d} t_{A}^{o}-e c_{A}^{d}<0$. In the absence of distance charges for trucks, this may be an equilibrium when there is strong fuel tax competition for trucks and when the external cost of diesel cars is high. Country A can still benefit from a substitution $d T_{A}=-d t_{A}>0$ but the total benefit will be smaller as the substitution must balance the increasing distortion for diesel cars.

In summary, the introduction of distance charging for trucks not only risks the evolution of an inefficient charging level for international truck traffic but also an additional distortion in the pricing of diesel cars.

\section{Concluding remarks}

We have shown that when the only policy option is using a fuel tax for trucks, there is a large risk that countries will set it at an inefficient level due to tax competition. The tax may be set above or below the external costs depending on the degree of fuel tax competition, which ultimately depends on the characteristics of the countries and the market. Small countries may prefer low fuel taxes as this allows them more international trucks fueling in their home country.

If an additional policy instrument is introduced in the form of distance charges, we show that a Nash equilibrium is likely to contain only distance charges if there are no diesel cars. The same tendency will persist if the fuel tax must also internalize the externalities of diesel cars: 
fuel taxes will remain but they will decrease. The end result with distance charges for trucks will be a level of taxation of international trucking that is strictly larger than the external cost. The tax on the use of diesel cars, however, will be too small.

Our paper provides many policy implications for federations (like the EU) where distance charges are being introduced.

In this paper we have first shown that distance charges for trucks are contagious. Whenever one country implements them, it forces the neighboring countries to follow suit. The end result is charges on international trucking above the external cost and diesel excises for cars that are too low. Contagious policies that are welfare decreasing should be contained and other federations manage to do this. The different US states and the bordering Canadian provinces also run the risk of intensive diesel fuel tax competition. None of the different states introduced distance charging due to a fuel tax sharing agreement (called "IFTA", see Denison \& Facer, 2005) in which almost all US states and the Canadian provinces participate. Fuel taxes differ among states but the revenues are redistributed according to the distances covered in each state. The redistribution of fuel tax revenues dilutes the incentives to engage in fuel tax competition and thus also reduces the motives for introducing distance charges. In fact, if disregarding fuel efficiency effects, the international fuel tax sharing arrangement has transformed the fuel tax into a de facto distance charge.

Second, no such fuel tax sharing agreement exists in the EU, and as such there is scope for the regulation of fuel taxes and distance charges. As long as fuel taxes were the dominant charging mechanism for trucks, tax competition by small countries drove the charges down. This resulted in minimum tax agreements, which worked but kept fuel taxes low. We show in this paper that the distance charges are higher than the external costs, which now calls for the imposition of upper limits on distance charges rather than minimums. The formulation of an upper limit is difficult because external costs are country specific. This problem is partly solved by linking the level of distance charges to infrastructure costs, which can be more easily observed than external costs. This can solve the asymmetric information problem for external congestion costs, as they can be directly linked to infrastructure costs ${ }^{21}$. In this cap there is an exception for mountainous areas who can charge more. This applies mainly to

\footnotetext{
${ }^{21}$ With constant returns to scale for road capacity, the revenues of correct congestion tolls can cover the costs of optimal capacity. The best the local governments can do under a cap for the infrastructure charges is to implement the correct congestion charges (Van der Loo \& Proost, 2013).
} 
Austria, and the reason is not so much that mountainous areas have higher external costs, rather it is to allow Austria to benefit from its position as alternative to Switzerland.

Third, the set-up costs for a distance-charging scheme are high and this puts small countries at a disadvantage. Compare Switzerland and Luxemburg. Switzerland has a strategic advantage as a transit country and can afford the set-up costs as it will be able to charge a high margin to cross the country (its charges are 3 to 4 times more than its neighbors). Luxemburg can be bypassed easily, so it will have to continue to use slightly lower fuel excises than the neighbors; however, this strategy is risky once the neighbors with transit charges start to cut their own diesel excises, as we have shown they are likely to do. Given the high set-up costs, Luxemburg may be one of the last countries to introduce distance charges.

Fourth, technology progress allows for differentiated distance charges in respect to emissions and weight category of the truck. In theory, this flexibility can give rise to distance charges that have too low of a differentiation for environmental damage. The reason is that a government, if viewed as a monopolist interested in raising revenues, will not pass the environmental cost to the drivers. Interestingly, in Germany, the possibility for differentiating the distance charges according to environmental criteria ended up as a loophole to favor German truck owners. Very green trucks were charged much less and Germany subsidized the purchase of very green trucks by German truckers. The more polluting trucks ended up in neighboring countries with less stringent environmental charges (Vierth et.al., 2015).

Fifth, one of the side effects of tax competition over diesel fuel for international trucks has been the steady progress of diesel cars in Europe, where diesel has a market share of over 50 percent in many countries. As we have shown, the introduction of distance charging for trucks will only push diesel excises further down. Diesel cars are considered problematic as, in comparison with gasoline cars, they pollute more and generate less tax revenue. The only solution is the use of more specific instruments to discourage the use of diesel cars: higher registration and purchase taxes or stricter pollution standards.

Finally, the lower diesel excises that result with and, although less so, without the introduction of distance charges is not a problem for climate policy in Europe because the current fuel excises are still much higher than the implicit carbon price in other sectors of the economy. Lower diesel excises are therefore efficiency-enhancing in terms of climate policy, as they reallocate mitigation burdens in a more cost effective manner, but they are problematic when they are the only instrument used to price all externalities. 


\section{References}

Corts, K. S. (1998),Third-degree price discrimination in oligopoly: all-out competition and strategic commitment. The RAND Journal of Economics, 306-323.

De Borger, B., Dunkerley, F. and Proost S.(2007), Strategic investment and pricing decisions in a congested transport corridor. Journal of Urban Economics 62, 294316.

De Borger, B., Dunkerley, F. and Proost S.(2008), The interaction between tolls and capacity investment in serial and parallel transport networks. Review of Network Economics 7, 1-23.

De Borger, B., Proost, S. (2012), Policy competition in the transport sector: a selective survey of the literature, Economics of Transportation, 1, 35-48

De Borger, B., Proost, S., Van Dender, K. (2005), Congestion and tax competition in a parallel network. European Economic Review, 49(8), 2013-2040

De Jong, G., Schroten, A., Van Essen, H., Otten, M., Bucci, P., (2010), Price sensitivity of European road freight transport -towards a better understanding of existing results, Report 9012-1 for Transport \& Environment

Denison, D., Facer, R. L. II. (2005), Interstate Tax Coordination: Lessons from the International Fuel Tax Agreement, National Tax Journal LVIII:3, p. 591-603.

Diamond, P. A. \& Mirrlees, J. A. (1971), Optimal taxation and public production I: Production efficiency. The American Economic Review, 61,8-27. 
European Commission. (2014), Update of the Handbook on External Costs of Transport. Final Report for the European Commission: DG Move. RicardoAEA/R/ED57769. London, UK: Ricardo-AEA. https://www.ifr.unikiel.de/de/forschung/handbook-external-costs-transport-2014.pdf.

Eurostat,http://epp.eurostat.ec.europa.eu/statistics_explained/index.php?title=File: National_and_international_road_transport_of_goods,_2012_(1)_(\%25_based_on _million_tkm_of_laden_transport)_YB14.png\&filetimestamp=20140311101514

Evers, M., Mooij, R.A. de, Vollenbergh, J.R.H., (2004), Tax Competition Under Minimum Rates: The Case of European Diesel Excises. CESifo Working Papers, No. 1221.

Hamilton, Carl J., J Eliasson (2013), Costs and benefits of the European directive on road tolling interoperability, Transportation Research Part C, 30, 221-238

Hylen, B., Kauppila, J., Chong, E., (2013), Road Haulage Charges and Taxes, DP 2003-08, ITF

Kanbur, A.,Keen M.(1993), Jeux sans frontières: tax competition when countries differ in size, American Economic Review 83, 877-892.

Mayeres, I.,Proost, S. (1997). Optimal tax and public investment rules for congestion type of externalities. The Scandinavian Journal of Economics, 99(2), 261-279.

Mun, S. , K. Ahn K. (2008), Road pricing in a serial network, Journal of Transport Economics and Policy 42, 367-395.

Paizs, L. (2013), Asymmetric competition in the setting of diesel excise taxes in EU countries. Acta Oeconomica, 63(4), 423-450. 
Rietveld P., van Woudenberg S. (2005), Why fuel taxes differ, Energy Economics 27 (2005) 79- 92

Thisse, J. F. \& Vives, X. (1988). On the strategic choice of spatial price policy. The American Economic Review, 122-137.

Van der Loo, S., Proost, S. (2013), The European road pricing game: how to enforce optimal pricing in high-transit countries under asymmetric information, Journal of Transport Economics and Policy, 47, 399-418.

Vierth, I.,Schleusser H. (2012), Impacts of different environmentally differentiated truck charges on mileage, fleet composition and emissions in Germany and Sweden, CTS working paper 2012:22

Vierth, I., Schleusser H., Mandell S.(2015), Road Freight Transport Policies and their Impact - a Comparative Study of Germany and Sweden, CTS working paper 2015:16

Weismann, P. (2013), The Genesis of the Eurovignette directive, European Transport | Trasporti Europei, 53, Paper n ${ }^{\circ}$ 2, ISSN 1825-3997

Wilson, J. D. (1999), Theories of tax competition. National Tax Journal, 269-304. 
Appendix 1, map illustrating the policy mix in the EU.
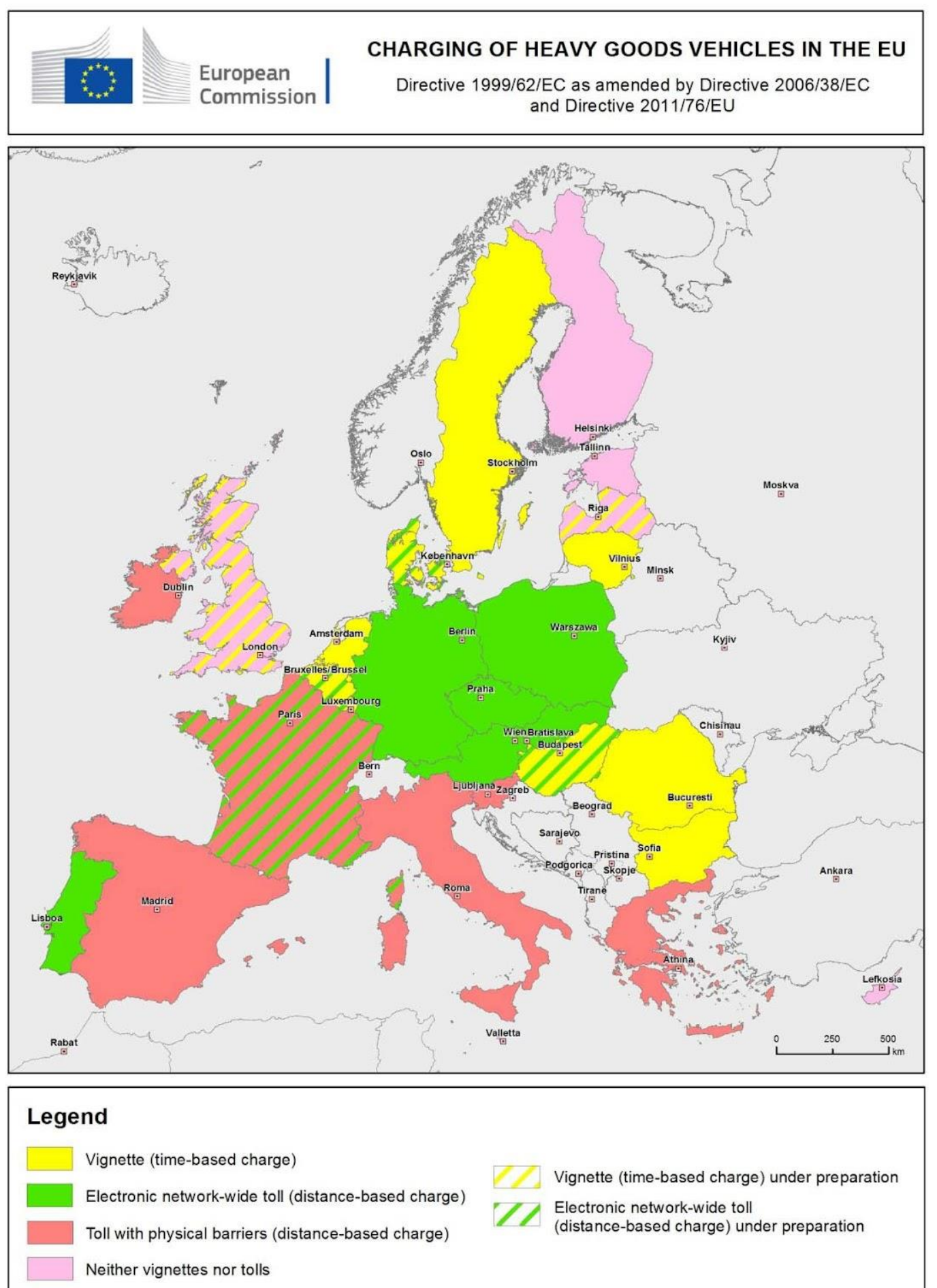

Vignette (time-based charge) under preparation

Electronic network-wide toll

(distance-based charge) under preparation

\section{Appendix 2 Proof of Proposition 1}


Consider first an internal solution, where both fuel taxes are positive. When demand for truck trips is inelastic, the first-order condition for a maximum of the national objective function of country A given by (6) reduces to

$$
-0.5 \frac{d G_{A}}{d t_{A}} D+\frac{d \sigma}{d t_{A}} \sigma D t_{A}+\sigma D=0
$$

Solving this equation with respect to $t_{\mathrm{A}}$ and repeating the exercise for country $\mathrm{B}$ gives the reaction functions and the candidate Nash equilibrium:

$$
\begin{aligned}
& t_{A}\left(t_{B}\right)=\frac{\gamma}{3 \rho}+\frac{t_{B}}{3} \quad t_{B}\left(t_{A}\right)=\frac{1-\gamma}{3 \rho}+\frac{t_{A}}{3} \\
& t_{A}^{N}=\frac{1}{8 \rho}+\frac{2 \gamma}{8 \rho} \quad t_{B}^{N}=\frac{1}{8 \rho}+\frac{2(1-\gamma)}{8 \rho}
\end{aligned}
$$

This is a candidate Nash equilibrium in pure strategies. The Nash equilibrium exists because, for acceptable parameter values $0<\gamma<1$ and $\rho>0$, the reaction functions are continuous and have a solution with positive taxes.

Consider next potential equilibriums where $t_{A}=0$ and $t_{B}>0$; can this be an equilibrium? No, as country A's objective function is for $t_{A}=0$ and $t_{B}>0$ always strictly increasing in $t_{A}$. The same reasoning holds for country $\mathrm{B}$, so the equilibrium fuel tax rates are always positive.

\section{Appendix 3 Derivation of Prop 2}

Derivation of the Nash equilibrium

Starting from the first order condition (7), imposing symmetry implies: $t_{A}=t_{B}$ and $\sigma=\gamma$, and one obtains, after multiplying by $(1 / \gamma)$ :

$$
\begin{array}{ll}
t_{A}\left[\frac{\delta d}{\delta t_{A}}+\frac{\delta D}{\delta t_{A}}-2 \rho\right]=\left[\frac{\delta d}{\delta t_{A}}+\frac{\delta D}{\delta t_{A}}\right] e c-\sigma D & \\
t_{A}^{N}=t_{B}^{N}=\frac{z}{z-2 \rho D} e c-\frac{\gamma}{z-2 \rho D} D \quad \text { Where } z=\frac{\delta d}{\delta t_{A}}+\frac{\delta D}{\delta t_{A}}
\end{array}
$$

Effect of increase in $D$ on Nash equilibrium

$$
\frac{\delta t^{N}}{\delta D}=\frac{2 \rho}{(-z-\rho D)^{2}}+\frac{-\gamma z}{(-z-\rho D)^{2}}>0
$$


Derivation of the critical value of $t^{*}$ for which value there is no longer a Nash equilibrium in pure strategies

We look for the value of $\mathrm{t}_{\mathrm{A}}{ }^{*}$ such that it produces the same welfare as $t_{\mathrm{A}}=\mathrm{ec}>\mathrm{t}^{\mathrm{N}} \mathrm{B}$. Let the objective function of country A be $\Omega\left(\mathrm{t}^{\mathrm{N}} \mathrm{A}^{*}, \mathrm{t}_{\mathrm{B}}{ }^{*}\right)$ when it charges the symmetric Nash equilibrium taxes and let $\Omega\left(\mathrm{t}_{\mathrm{A}}=\mathrm{ec}, \mathrm{t}_{\mathrm{B}}{ }^{*}\right)$ be the value of the objective function when it switches to charging the external cost.

The two objective functions will have the same value when the deadweight loss from charging too low of a tax for local traffic equals the revenue from fuel sales to international trucks. This implies a value for the fuel tax that solves the following equation:

$$
\frac{b \gamma}{2}\left(e c-t_{A}^{*}\right)^{2}=\gamma D t_{A}^{*}
$$

With solution

$$
t_{A}^{*}=0.5\left[2 \mathrm{ec}+\frac{2 D}{b}-\sqrt{\frac{2 D}{b}} \sqrt{4 e c+\frac{2 D}{b}}\right]
$$

But as this fuel tax is also a potential symmetric Nash equilibrium, it also must satisfy (9), which gives the implicit equation in $\rho$ :

$$
t_{A}^{*}=0.5\left[2 \mathrm{ec}+\frac{2 D}{b}-\sqrt{\frac{2 D}{b}} \sqrt{4 e c+\frac{2 D}{b}}\right]=t_{A}^{N}=\frac{0.5 \mathrm{~b}}{0.5 \mathrm{~b}+2 \rho^{*} D} e c+\frac{0.5}{0.5 \mathrm{~b}+2 \rho^{*} D} D
$$

\section{Appendix 4 Proof of Proposition 3}

We have three possible regimes for the fuel market share: $\sigma=0,0<\sigma<1$ and $\sigma=1$.

We start with the two extreme cases.

If $t_{A}>>t_{B}$, we have $\sigma=0$, and the preferred $t_{A}=e c_{A}$.

If $t_{A}<<t_{B}$, we have $\sigma=1$, and the preferred $t_{A}$ is derived from the following first order condition for a maximum; using (7) and $\sigma=1$, we have:

$$
\gamma \frac{\partial d_{A}}{\partial t_{A}}\left(t_{A}-e c_{A}\right)-0.5 D+\frac{\partial D}{\partial t_{A}}\left(t_{A}-e c_{A}\right)+D=0
$$

Which leads to: 


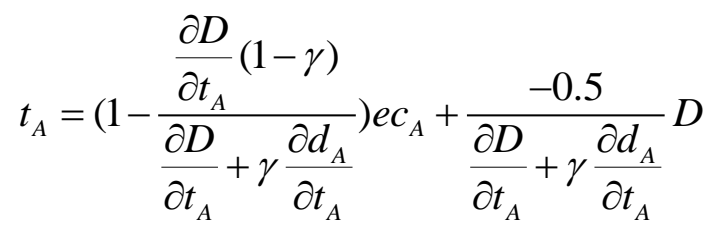

When we have an internal equilibrium we start again with the first order condition (7).

$$
-\gamma d_{A}+\gamma \frac{\partial d_{A}}{\partial t_{A}}\left(t_{A}-e c_{A}\right)+\gamma d_{A}-0.5 D \frac{\partial G_{A}}{\partial t_{A}}+\frac{\partial D}{\partial t_{A}}\left(\sigma t_{A}-\gamma e c_{A}\right)+\frac{\partial \sigma}{\partial t_{A}} D t_{A}+\sigma D=0
$$

Simplifying for inelastic international demand, we obtain the two reaction functions:

$$
\begin{aligned}
& t_{A}=e c_{A}-\frac{D}{\frac{\partial d_{A}}{\partial t_{A}}}-\frac{\rho D}{\gamma \frac{\partial d_{A}}{\partial t_{A}}} t_{B} \\
& t_{B}=e c_{B}-\frac{D}{\frac{\partial d_{B}}{\partial t_{B}}}-\frac{\rho D}{(1-\gamma) \frac{\partial d_{B}}{\partial t_{B}}} t_{A}
\end{aligned}
$$


Appendix 5 Proof of Proposition 4

PROP 4 Assume distance charges can be used and that there are other tax instruments for diesel cars; then a Nash equilibrium cannot involve diesel fuel taxes and $0<\sigma<1$. The equilibrium distance charges are greater than the marginal external cost:

$t_{A}=t_{B}=0$

$T_{A}-e c_{A}=\frac{0.5 D}{\gamma(b+\beta)}>0$

$T_{B}-e c_{B}=\frac{0.5 D}{(1-\gamma)(b+\beta)}>0$

\section{PROOF}

We examine the case where in a potential Nash equilibrium $t_{A}, t_{B}>0$ and $0<\sigma<1$ : the international fuel market is shared between the two countries. For this case we will show that a country can always gain by substituting one Euro of diesel tax per kilometer by one Euro of distance charges per kilometer and that therefore such a potential equilibrium cannot be an equilibrium. Next we discuss briefly what happens when $t_{A}, t_{B}=\mathrm{o}$ and $\sigma=\mathrm{o}$ or 1 .

1. For $t_{A}, t_{B}>0$ and $\mathrm{o}<\sigma<1$ we will show that the value of the objective function of country A (the same reasoning holds for $\mathrm{B}$ ):

$$
\operatorname{CS}_{A}\left\{g_{A}\{.\}\right\}+d_{A}\{.\}\left(\gamma t_{A}+\gamma T_{A}-\gamma e c_{A}\right)+0.5 \operatorname{CS}\{G\{.\}\}+D\{.\}\left(\sigma t_{A}+\gamma T_{A}-\gamma e c_{A}\right)-I T_{A}
$$

can be increased by a marginal substitution $d T_{A}=-d t_{A}>0$ when the potential Nash equilibrium has $t_{A}, t_{B}>0$ and $0<\sigma<1$.

We need to examine first the effect of this substitution on the generalized costs in the potential Nash equilibrium:

$$
g_{A}=\gamma\left(c+t_{A}+T_{A}\right)
$$

So the generalized cost of local truck trips $\mathrm{g}_{\mathrm{A}}$ will not be affected by substituting $t$ and $T$. The generalized cost of international traffic is:

$$
G=c+\gamma T_{A}+(1-\gamma) T_{B}+\sigma\left(t_{A}, t_{B}\right) t_{A}+\left(1-\sigma\left(t_{A}, t_{B}\right)\right) t_{B}
$$


After the substitution we see that it also will not be affected:

$$
d G=\gamma d T_{A}+\left(\gamma-\rho\left(t_{A}-t_{B}\right)\right) d t_{A}-\rho t_{A} d t_{A}+\rho t_{B} d t_{A}=0
$$

We can now compute the effect of this $(t, T)$ substitution on the value of the objective function of country A. There will be no effect on the two first terms of the objective function as local consumer surplus and net revenues on local trips are unaffected by the substitution. There will also be no effect on the consumer surplus of international traffic. The only effect will be on the revenues from international traffic for country A:

$$
D\{\}\left[\gamma d t_{A}-\rho t_{A} d t_{A}+\gamma d t_{A}\right]=D\{\}\left[\rho t_{A} d T_{A}\right]>0
$$

So, as long as $t_{A}>0$ one can increase the value of the objective function by this substitution, so a Nash equilibrium cannot have $t_{A}, t_{B}>0$ and $0<\sigma<1$.

2. Assume that a Nash equilibrium exists with $t_{A}, t_{B}=0$ and we can use the first order optimal conditions for A and B that will characterize the Nash equilibrium:

$$
\begin{gathered}
-\gamma d_{A}+\gamma \frac{\partial d_{A}}{\partial T_{A}}\left(T_{A}-e c_{A}\right)+\gamma d_{A}-0.5 D \frac{\partial}{\partial T_{A}}+\frac{\partial D}{\partial T_{A}}\left(\gamma T_{A}-\gamma e c_{A}\right)+\gamma D=0 \\
-(1-\gamma) d_{A}+(1-\gamma) \frac{\partial d_{B}}{\partial T_{B}}\left(T_{B}-e c_{B}\right)+(1-\gamma) d_{B}-0.5 D \frac{\partial G}{\partial T_{B}}+\frac{\partial D}{\partial T_{B}}\left((1-\gamma) T_{B}-(1-\gamma) e c_{B}\right)+(1-\gamma) D=0
\end{gathered}
$$

Which gives:

$$
T_{A}-e c_{A}=\frac{-0.5 D}{\frac{\partial d_{A}}{\partial T_{A}}+\frac{\partial D}{\partial T_{A}}}=\frac{0.5 D}{\gamma(b+\beta)}>0
$$

And

$$
T_{B}-e c_{B}=\frac{-0.5 D}{\frac{\partial d_{B}}{\partial T_{B}}+\frac{\partial D}{\partial T_{B}}}=\frac{0.5 D}{(1-\gamma)(b+\beta)}>0
$$


Therefore the distance charge is always larger than the external cost and the mark-up on external costs is higher in the smaller country. 